\title{
Spatio-temporal characteristics of the Agulhas Current retroflection
}

\author{
Guillaume Dencausse, Michel Arhan*, Sabrina Speich \\ Laboratoire de Physique des Océans, CNRS/IFREMER/IRD/UBO, Brest, IFREMER/Centre de Brest, B.P. 70, 29280 Plouzané, France
}

\section{A R T I C L E I N F O}

Available online 1 August 2010

Keywords:

Agulhas Current retroflection

Indo-Atlantic exchanges

Altimetry

Spatio-temporal variations

\begin{abstract}
A B S T R A C T
A 12.7-year series of weekly absolute sea surface height (SSH) data in the region south of Africa is used for a statistical characterization of the location of the Agulhas Current retroflection and its variations at periods up to 2 years. The highest probability of presence of the retroflection point is at $\sim 39.5^{\circ} \mathrm{S} /$ $18-20^{\circ} \mathrm{E}$. The longitudinal probability density is negatively skewed. A sharp eastward decrease at $22^{\circ} \mathrm{E}$ is related to detachments of the Agulhas Current from the continental slope at this longitude. The asymmetry in the central part of the distribution might reflect a westward increase of the zonal velocity of the retroflection point during its east-west pulsations. The western tail of the distribution reveals larger residence times of the retroflection at $14^{\circ} \mathrm{E}-15^{\circ} \mathrm{E}$, possibly related to a slowing down of its westward motion by seamounts. While the averaged zonal velocity component of the retroflection point increases westward, its modulus exhibits an opposite trend, the result of southward velocity components more intense in the northeastern Agulhas Basin than farther west. These meridional motions likely reflect influences by cyclones adjacent to the Agulhas Current south of the Agulhas Bank, and farther west in the Cape Basin. In the latter area, variations of the meridional motions result in different positions of the westernmost retroflection patterns relative to the neighbouring seamounts, likely influencing the future behaviour of Agulhas rings shed at these locations. Agulhas ring formation at an average yearly rate of 5.8, similar to previous findings, was observed to occur west of $\sim 19^{\circ} \mathrm{E}$, in the western half of the retroflection probability domain. A well-defined seasonal signal of the retroflection longitude was found throughout the first 5 years of the time series, characterized by amplitudes of $1-1.3^{\circ}$ of longitude, and western (eastern) extremes during austral summer (winter). This annual cycle was strongly phase shifted during and after the upstream retroflection event of 2000-2001.
\end{abstract}

(c) 2010 Elsevier Ltd. All rights reserved.

\section{Introduction}

The Agulhas Current, which flows southwestward along the eastern coast of South Africa, its retroflection in the region south of the Agulhas Bank, and its eastward continuation as the Agulhas Return Current at about $39^{\circ} \mathrm{S}$ (Fig. 1), constitute the western closure of the subtropical gyre of the South Indian Ocean. Owing to its utmost role in water exchanges between the Indian and Atlantic oceans, this Agulhas Current system has been studied extensively over the last decades (see Lutjeharms, 2006, for a review). Its general flow pattern could be inferred from early hydrographic observations (Harris and van Foreest, 1978), but its complex time-varying behaviour only began to be deciphered when remote-sensing satellite observations of the sea surface by infrared radiometry (Harris et al., 1978; Lutjeharms and van Ballegooyen, 1988a) or by altimetry (Feron and de Ruijter, 1992) became available.

\footnotetext{
* Corresponding author. Tel.: +33 298224285; fax: +33 298224496.

E-mail addresses: michel.arhan@ifremer.fr, marhan@ifremer.fr (M. Arhan).
}

Using data from a multi-ship survey, Harris and van Foreest (1978) provided a complete picture of the current as schematized in Fig. 1, including the northward loop of the Agulhas Return Current around the Agulhas Plateau. After Gründlingh (1978) using trajectories of satellite tracked buoys and Harris et al. (1978) using sea surface temperature obtained through satellite infrared imagery first suggested a bimodal retroflection of the Agulhas Current at preferred longitudes, Lutjeharms and van Ballegooyen (1988a), also using infrared thermal imagery, eventually disclosed the now well-known pulse-like behaviour of the Agulhas Retroflection. They found the retroflection to lie "between $16^{\circ}$ and $20^{\circ} \mathrm{E}$ with a loop diameter of $340 \mathrm{~km}$ ", and to "protrude westward at intervals of slightly more than one month, shedding pinched-off Agulhas rings... at its most westerly extension". This description also accounted for anticyclones that had been observed for a long time in the western part of the retroflection region (Duncan, 1968; Gordon et al., 1987; Lutjeharms and Gordon, 1987).

The importance of Agulhas rings for inter-oceanic exchanges brought about several studies of the shedding mechanism and its frequency. Using a correlation and principal component method on sea surface height (SSH) anomalies from satellite Geosat, Feron 


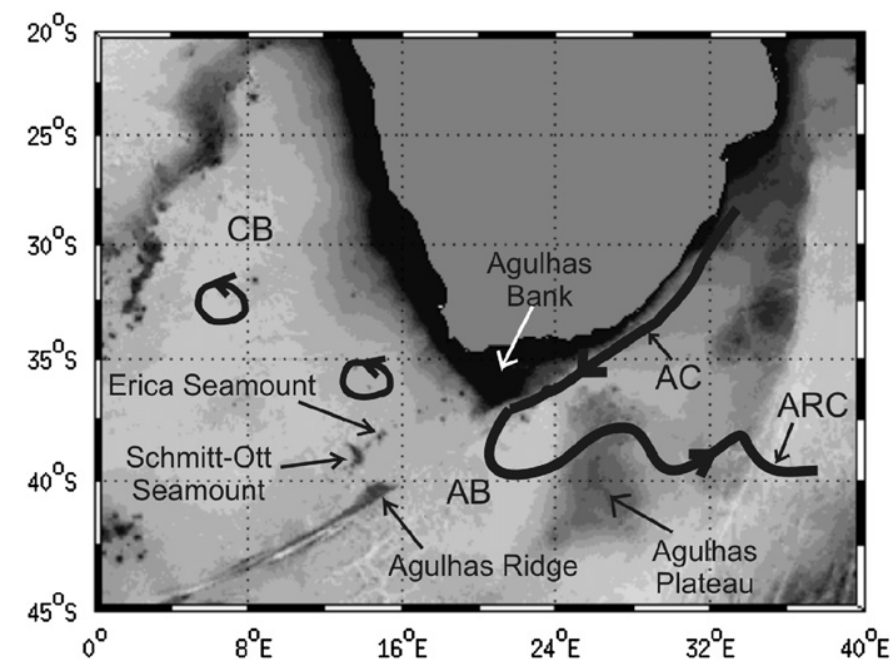

Fig. 1. Bathymetric map of the area of study, with the names of the main basins and topographic features cited in the text. The bold lines show the schematic track of the Agulhas Current (AC), Agulhas Return Current (ARC), and a few Agulhas rings. $\mathrm{CB}$ and $\mathrm{AB}$ stand for Cape Basin and Agulhas Basin, respectively.

and de Ruijter (1992) numbered 18 pulses of the retroflection system over 3 years, likely connected to the formation of Agulhas rings. Byrne et al. (1995), using the same data for tracking Agulhas rings across the South Atlantic, found 16-18 of these structures entering this ocean basin during the same time period. Goni et al. (1997) similarly counted 17 rings over 3 years passing through two TOPEX-POSEIDON ground tracks to the west of the retroflection region. Schouten et al. (2000), using the same method as Feron and de Ruijter (1992) on 4 years of TOPEX-POSEIDON Sea Height Anomaly data, confirmed a formation frequency slightly higher than 5 per year, yet with occasional long periods (over 4 months) without any shedding event.

Lutjeharms and van Ballegooyen (1984) suggested that the Agulhas retroflection on average protrudes farther west during the austral summer, but although they showed that the westward extent of the retroflection is anti-correlated with the intensity of the Agulhas Current, no well-defined seasonality has been observed in the latter. The seasonality of the SSH variability in the retroflection region seems better defined, with a summer maximum and winter minimum (Matano et al., 1998), in keeping with observations by Goni et al. (1997) that the number of rings translating in the region west of the retroflection is larger during the first half of each year. A reason for the difficulty in detecting seasonal variability in the Agulhas retroflection probably lies in the presence of superimposed inter-annual components. Upstream retroflection events are a major manifestation of this lower frequency variability: Such events designate periods during which the Agulhas Current retroflects at or east of the Agulhas Plateau, or $\sim 25^{\circ} \mathrm{E}$. Lutjeharms and van Ballegooyen (1988b) revealed such occurrences, and Quartly and Srokosz (2002) and de Ruijter et al. (2004) discussed a long-lasting one in 2000-2001.

Considering the results that are briefly summarized above, it appears that the detailed description of the Agulhas retroflection pulses and ring shedding process was mostly provided, from satellite thermal infrared imagery, in the work of Lutjeharms and van Ballegooyen (1988a). Satellite altimetry, though it corroborated the conclusions obtained from sea surface temperature, did not lead to as much improvement in the detailed description of the retroflection pulses as might have been hoped. A reason for this certainly lies in the fact that often only anomalies of SSH were available for these studies, not absolute SSH with the mean circulation signal included. This is particularly restricting in this region where the time-averaged SSH field shows spatial variations comparable in magnitude to those of the time variability. This has led authors to develop indirect methods to detect eddy spawning times, which may not be fit for detailed analyses of the retroflection itself. Another limitation of altimetry as used so far in this region is the relatively short duration of available time series (4-5 years at most), clearly not sufficient for studies of inter-annual variations, and even of seasonal variations likely perturbed by lower frequencies.

The recent availability of altimetry time series exceeding 10 years in duration and, especially, of absolute SSH products in which anomalies are combined to a mean sea level field (Rio and Hernandez, 2004), led us to undertake a new study of the Agulhas retroflection and of the spawning of Agulhas rings based on these improved and more numerous data. Our main objective was, using the absolute SSH data, to precisely define the "retroflection point" located at the western tip of the Agulhas retroflection and, owing to the time series length, to get significant statistical results on the spatio-temporal variations of this point and its relation to ring shedding events.

\section{Data and methods}

\subsection{Data}

We used absolute SSH fields distributed by the Archiving, Validation and Interpretation of Satellite Oceanographic data base (AVISO). These altimeter products are provided by Ssalto/Duacs with support from the French Centre National d'Etudes Spatiales (http://www.aviso.oceanobs.com/duacs/). They combine a multisatellite sea surface height anomaly (TOPEX/POSEIDON, JASON-1, ERS: Le Traon et al., 1998; Ducet et al., 2000), and a time-averaged dynamic topography field itself calculated using in situ data, altimetric data, and the EIGEN-GRACE03S geoïd (Rio and Hernandez, 2004). For brevity we mean the absolute SSH when writing "SSH", and specify "anomaly" when needed. Fields of surface geostrophic velocity deduced from the SSH data are also used.

All parameters are gridded with an interval of $1 / 3$ rd of a degree in latitude and longitude using an objective analysis, and are available at a weekly rate starting from October 14,1992 . For this study, we used the time series up to May 18,2005 , that is, a total of 658 weeks ( 12.7 years).

\subsection{Determination of the retroflection point in the weekly SSH fields}

In the SSH field averaged over the study period (Fig. 2), an increased gradient in the range $1.5 \mathrm{~m}<\mathrm{SSH}<2.1 \mathrm{~m}$ marks the Agulhas Current and Agulhas Return Current. Having observed that the gradient is still more pronounced and occurs in the same SSH range in the weekly fields, a search method for the retroflection point directly based on the SSH values was defined as follows. We first chose a critical value SSHcr representative of the core of the current. This requires determining the relation between SSH and the surface geostrophic velocity in the weekly SSH fields, which proved delicate to perform at the retroflection point itself because of its turbulent environment, but easier across the Agulhas Current and Agulhas Return Current. Fig. 3 shows these relations at $23^{\circ} \mathrm{E}$, a longitude immediately east of the retroflection pulses region. The curves for the two currents are symmetric, and point to current cores between $\mathrm{SSH}=1.6$ and $1.8 \mathrm{~m}$. We chose the value $1.7 \mathrm{~m}$.

Based on this SSHcr value, the latitudinal domain of the retroflection loop ( $\mathrm{SSH}>\mathrm{SSH}$ cr) was determined, for each weekly 
SSH field, at a longitude located well to the east of the retroflection $\left(35^{\circ} \mathrm{E}\right)$. Then progressing westward, the latitudinal segment of the retroflection loop was determined at each grid

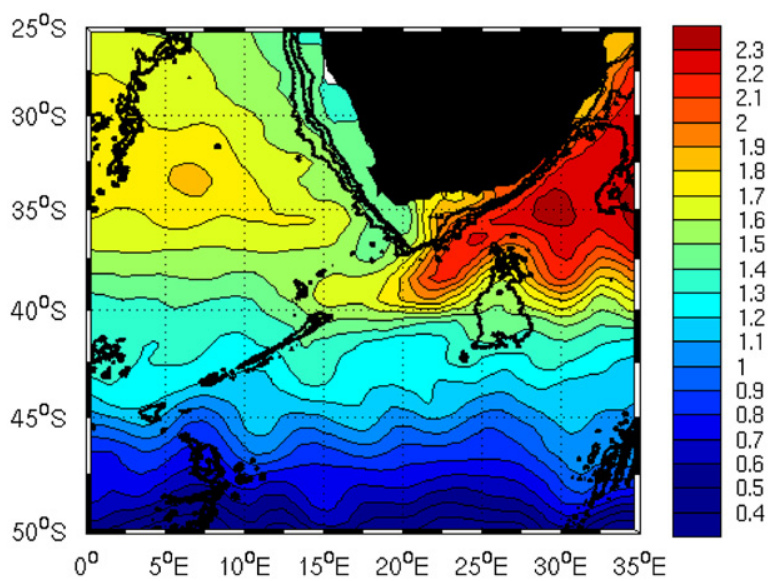

Fig. 2. Averaged field of SSH (m) for the period 12 October 1992-18 May 2005. Contour interval is $0.1 \mathrm{~m}$.

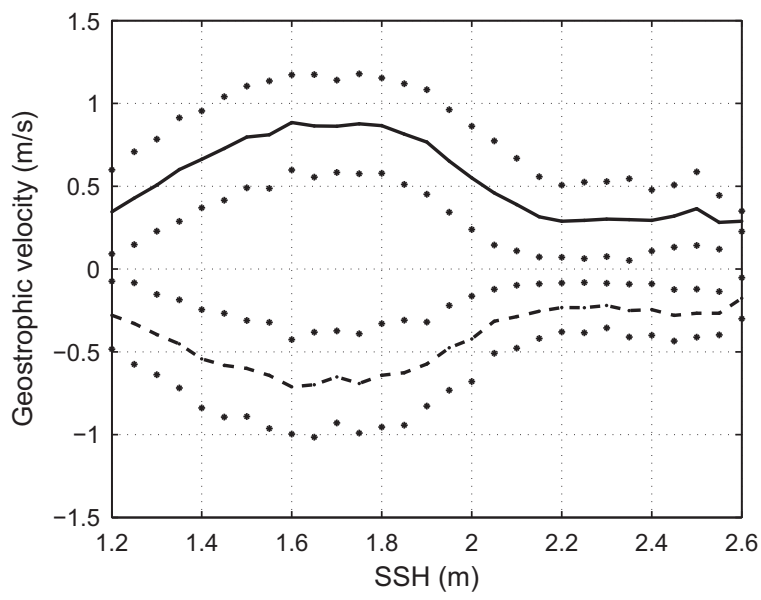

Fig. 3. Relation between surface geostrophic velocity (positive eastward) and SSH along $23^{\circ} \mathrm{E}$, deduced from all weekly SSH fields. The solid curve shows the relation in the Agulhas Return Current, the dashed curve in the Agulhas Current. Stippled curves limit the plus/minus one standard deviation domains. longitude, until no location with $\mathrm{SSH}>\mathrm{SSH}$ cr was found. The retroflection point was ascribed the last longitude where one or more grid points had values of SSH exceeding SSHcr. Determining the latitude of the retroflection from the same grid points, however, sometimes gave an unstable result, for the nearly meridional western tip of the retroflection may cause significant latitudinal shifts of the westernmost selected points from one week to the next. For this reason, the retained retroflection latitude is the average latitude of grid points with $\mathrm{SSH}>\mathrm{SSHcr}$ at the three westernmost longitudes (therefore spanning a $1^{\circ}$ longitude width).

Using the value $\mathrm{SSHcr}=1.7 \mathrm{~m}$, however, anticyclonic eddies in the vicinity of the retroflection were observed to sometimes pull the search too far westward (Fig. 4a). In such cases we used a higher critical value $\mathrm{SSHcr}=1.9 \mathrm{~m}$ representative of the inner sides of the Agulhas Current and Agulhas Return Current (Fig. 3). The density of probability of distances between the retroflection points obtained from the two criteria (Fig. 4b) exhibits a pronounced maximum at $\sim 30 \mathrm{~km}$, a decrease to a low value at about $150 \mathrm{~km}$, and weaker residual values beyond the latter distance. The $0-150 \mathrm{~km}$ range clearly represents the (most numerous) cases when both positions are in the retroflection current whereas distances higher than $150 \mathrm{~km}$, as illustrated in Fig. 4a, reflect the presence of an eddy still connected to the main retroflection by SSH values between 1.7 and $1.9 \mathrm{~m}$. This led us to use $\mathrm{SSHcr}=1.7 \mathrm{~m}$ whenever the distance was lower than $150 \mathrm{~km}$, and $\mathrm{SSHCr}=1.9 \mathrm{~m}$ otherwise.

As an illustration of the correct determination of the retroflection point, we show in Fig. 5 the zonal cross-section of averaged surface meridional geostrophic velocities at the retroflection latitude. Although a limited number of weekly estimated retroflection points lie slightly east of the current core (those obtained using $\mathrm{SSHcr}=1.9 \mathrm{~m}$ ), this does not show on the averaged curve, as the velocity maximum is located at the retroflection point longitude. The retroflection current has an averaged southward velocity of $0.78 \pm 0.37 \mathrm{~m} / \mathrm{s}$ and an averaged width slightly exceeding $200 \mathrm{~km}$. At about $80 \mathrm{~km}$ west of the current core, velocities reverse to a northward direction, a likely indication of the frequent presence of just-detached Agulhas rings west of the retroflection.

The method described above provides a 12.7-year time series of retroflection points, whose spatial density of probability is displayed in Fig. 6. In the same figure are shown the mean latitudinal positions of the retroflection point at each longitude (yellow line) and the associated standard deviation intervals. Nearly all retroflection points were found in the Agulhas Basin. a

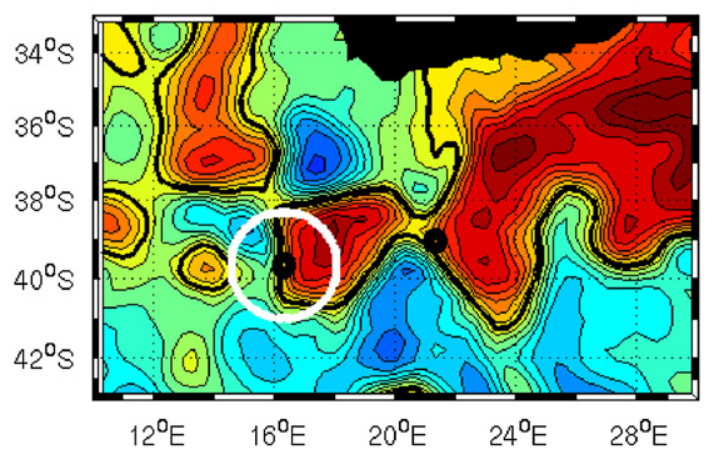

b

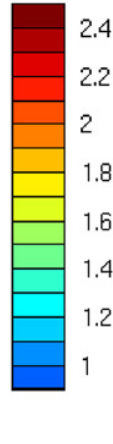

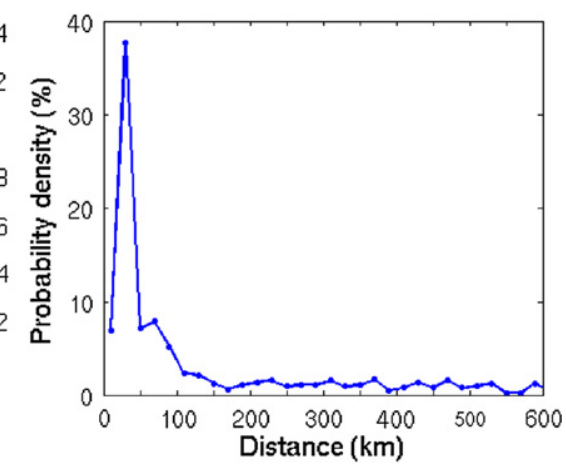

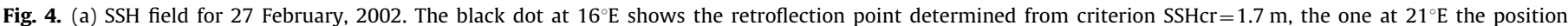

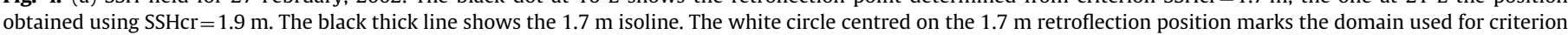

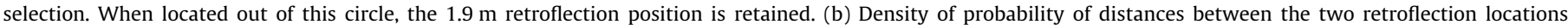
determined from criteria 1.7 and $1.9 \mathrm{~m}$. 


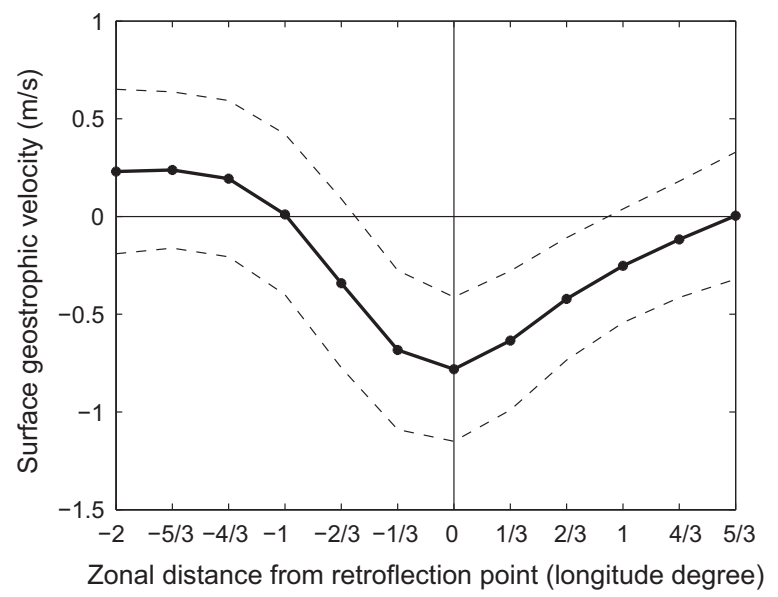

Fig. 5. Zonal cross-section of averaged meridional velocities at the retroflection latitude with the plus/minus one standard deviation band. The weekly retroflection longitudes were shifted to a common position (here taken as the origin of the horizontal axis) in order to compute the averaged velocities.

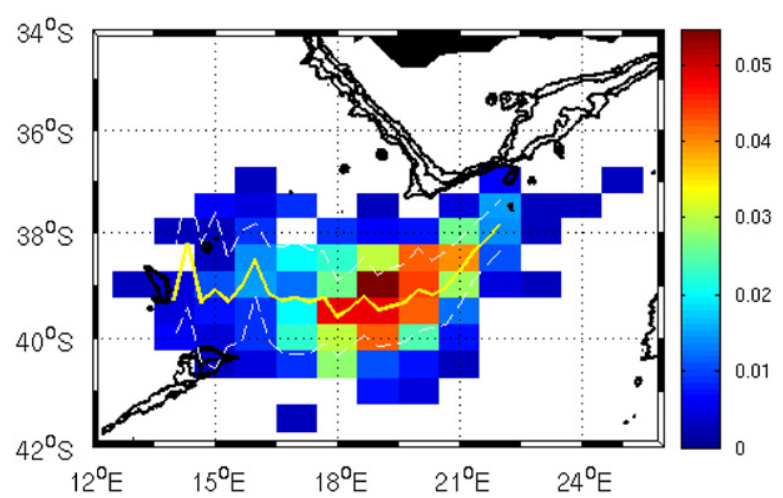

Fig. 6. Spatial density of probability of the retroflection point. The yellow line shows the mean latitudinal position of the retroflection at each longitude (white stippled lines mark the plus/minus one standard deviation band). Bathymetric contours are 500, 1000, 2000 and $2500 \mathrm{~m}$. Color bar gives the probability density scale.

Only a small fraction was located west of the Schmitt-Ott seamount, in the southeastern Cape Basin (Fig. 1), and east of the Agulhas Plateau (the latter retroflection positions do not appear in Fig. 6 but are discussed below). The mean retroflection track shows two main domains, one orientated northeastsouthwest to the east of $19^{\circ} \mathrm{E}$, and another one nearly zonal west of this longitude. We observe, however, an increased latitudinal variability west of $\sim 17^{\circ} \mathrm{E}$. This might reveal an influence of the neighbouring topography on the westernmost retroflection positions, although the statistical significance of the distribution decreases westward with the number of retroflection points sampled.

\subsection{Detection of Agulhas ring spawning}

This detection rests on a visual examination of SSH weekly maps, which unambiguously shows the detachment of anticyclonic structures from the Agulhas retroflection. Spawning events generally go with an eastward jump of the retroflection point, from the west to the east of the detached structure. While many of these structures enter the South Atlantic where they may subsequently subdivide or merge, others are partially or totally reabsorbed in the retroflection. The main difficulty when

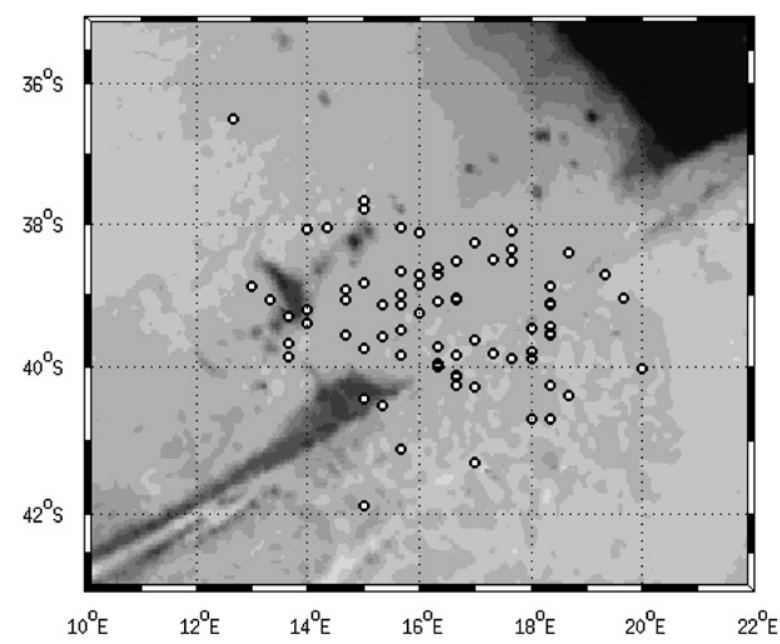

Fig. 7. Retroflection points on the dates of the 73 definitive eddy sheddings.

detecting Agulhas ring formation relates to events of that kind. It was settled using conventional criteria based on the time series of the retroflection point.

We first considered that a re-absorption occurred when an initially separated anticyclonic structure found itself anew to the east of the retroflection point for 2 weeks or more. Re-absorptions of only 1 week were ignored. With this definition, anticyclone detachments were regarded as definitive when at least a part of the detached structure was not reabsorbed by the retroflection. Temporary detachments were defined when the totality of a separated structure is reabsorbed (for at least 2 weeks). Finally, there were observations of simultaneous detachments of several structures from the retroflection, and of subdivisions of anticyclones the week following their detachments. We only counted one detachment in such cases. With these definitions, the weekly field preceding the observation of a specific detachment determined the "detachment date", and was used to locate the corresponding position of the retroflection. We identified 73 definitive and 3 temporary shedding events over the 12.7-year time series. Fig. 7 shows the locations of the retroflection point at the dates of the definitive separations, nearly all located in the western Agulhas Basin.

\section{Spatial characteristics of the Agulhas retroflection}

The time series of the retroflection longitude in Fig. 8 exhibits the pulse-like pattern of the retroflection described by Lutjeharms and van Ballegooyen (1988a), namely, periods of progressive westward motions followed by abrupt eastward shifts when an Agulhas ring is shed. A notable variation to this basic pattern, however, resides in abrupt westward shifts of the retroflection point, observed at several dates throughout the time series. These occur when a previously detached anticyclone is totally or partly reabsorbed by the retroflection. An example of total re-absorption is recognized at the beginning of 1993, when a sudden westward displacement of the retroflection followed a temporary eddy detachment. Mid-1994, on the other hand, provides an example of a partial re-absorption. In this instance, the eddy detachment preceding the abrupt westward shift was definitive, indicating that a part of the detached ring was not reabsorbed.

The probability distribution of the retroflection longitude (Fig. 9a) is centred on the mean value $18.85^{\circ} \mathrm{E}$, with a standard deviation of $2.2^{\circ}$ of longitude. It is relatively close to a normal distribution, with a skewness of 0.1 , yet has a high kurtosis of 3.95 mostly due to a set of values between $26^{\circ} \mathrm{E}$ and $28^{\circ} \mathrm{E}$. These values 

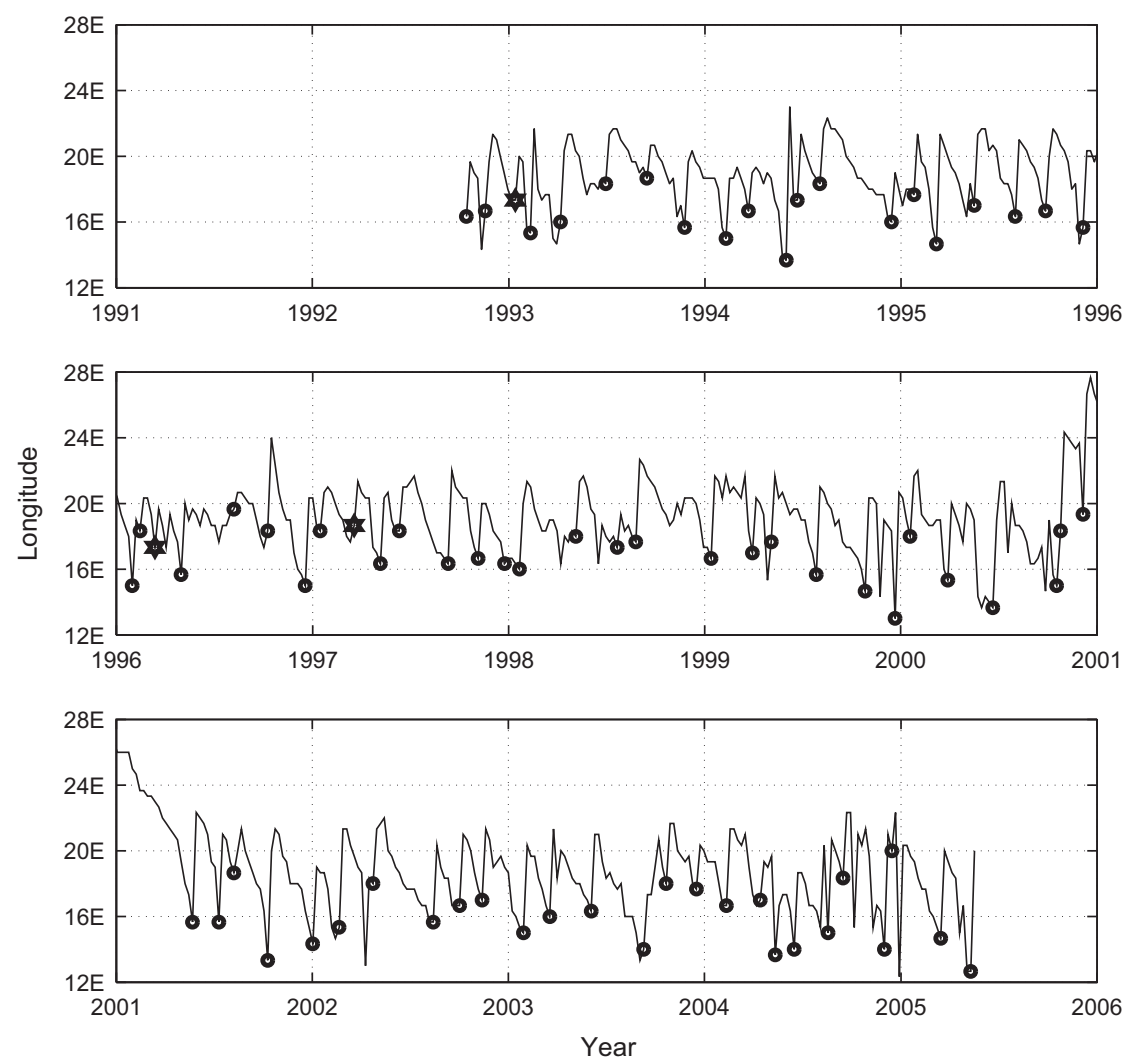

Fig. 8. Time series of the longitude of the retroflection point. Dots (stars) mark definitive (temporary) Agulhas ring shedding events.

are related to the upstream retroflection event of 2000/2001 (Fig. 8) which was analysed by de Ruijter et al. (2004). Excluding the corresponding cycle of westward motion/eastward shift of the retroflection point from the time series (that is, the period December 13, 2000-May 16, 2001), a distribution likely more representative of the usual retroflection variability is obtained (Fig. 9b). This new distribution, which corresponds to the twodimensional one displayed in Fig. 6 , has a mean at $18.7^{\circ} \mathrm{E}$, and a standard deviation of $2^{\circ}$ of longitude. It is worth mentioning that the locations of the retroflection points at the times of the 73 definitive shedding events (Fig. 7), which themselves have an average longitude of $16.3 \pm 1.7^{\circ} \mathrm{E}$, nearly all lie west of the average longitude of the retroflection point $\left(18.7^{\circ} \mathrm{E}\right)$. A rule of thumb may therefore be that Agulhas ring shedding takes place in the western half of the overall distribution function of the retroflection point.

Though now having a kurtosis of 3.03, the probability distribution of Fig. 9b significantly differs from a Gaussian law, with a negative skewness of -0.5 . Such skewness reflects an asymmetry of the distribution which can be analysed by comparing it with the best fit Gaussian law. To the east of the maximum, the retroflection probability density is high relative to the Gaussian law in the interval $20^{\circ} \mathrm{E}-22^{\circ} \mathrm{E}$, and lower than the Gaussian probability densities farther east. The opposite is observed on the western side of the distribution, with values below those of the Gaussian law near the central longitudes, and exceeding the latter in the western tail of the distribution.

Starting from the east, the weak probability density found east of $22^{\circ} \mathrm{E}$ should be mostly ascribed to the $\sim 5$ months that the retroflection point spent at these longitudes during the 2000-2001 event. Apart from this event, only 6 brief excursions east of $22^{\circ} \mathrm{E}$ are found in Fig. 8, of which the most significant reached $24^{\circ} \mathrm{E}$ in October 1996 . Notwithstanding these few exceptions, the abrupt westward increase of the probability density at $22^{\circ} \mathrm{E}$ suggests to regard this longitude as the eastern limit of the retroflection. This limit is apparently not directly related to the Agulhas Plateau, the western border of which lies farther east at $24^{\circ} \mathrm{E}-25^{\circ} \mathrm{E}$, but more likely to the geometry of the Agulhas Bank, whose eastern border exhibits a change of orientation at $22^{\circ} \mathrm{E}$ (Fig. 6). This likely relation of the retroflection to the continental slope configuration is further discussed below.

In the central part of the probability density curve (between $15^{\circ} \mathrm{E}$ and $22^{\circ} \mathrm{E}$ ), the highest values observed at $18^{\circ} \mathrm{E}-21^{\circ} \mathrm{E}$ on the upper eastern flank of the distribution result from this longitude band being common to nearly all retroflection pulses (Fig. 8). The east-west asymmetry might also be related to observations that the westward motions of the retroflection point occur at velocities increasing westward (Lutjeharms and van Ballegooyen, 1988a). This implies longer residence times, and a higher spatial probability density, in the eastern half of the central retroflection domain $\left(18^{\circ} \mathrm{E}-21^{\circ} \mathrm{E}\right)$. An average westward acceleration of the retroflection point in the band $15^{\circ} \mathrm{E}-22^{\circ} \mathrm{E}$ was confirmed using the retroflection longitude time series (dashed line of Fig. 10), with velocities of $\sim-0.04 \mathrm{~m} / \mathrm{s}$ at $22^{\circ} \mathrm{E}$ and $\sim-0.07 \mathrm{~m} / \mathrm{s}$ at $15^{\circ} \mathrm{E}$. The opposite variation at $14^{\circ} \mathrm{E}-15^{\circ} \mathrm{E}$ might reflect a real slowing down close to bathymetric obstacles (Fig. 6), or a less accurate estimate of the averaged westward velocity at $14^{\circ} \mathrm{E}$, resulting from less frequent retroflection occurrences there. Incidentally, the time series of the retroflection positions used here reveals that the averaged westward velocity increase only holds for the zonal component of the retroflection point displacements. The velocity modulus, computed using the zonal and meridional components averaged over $1^{\circ}$ longitude intervals, even exhibits an average westward decrease, from about $0.08 \mathrm{~m} / \mathrm{s}$ at $21^{\circ} \mathrm{E}-22^{\circ} \mathrm{E}$ to about $0.065 \mathrm{~m} / \mathrm{s}$ at $14^{\circ} \mathrm{E}-15^{\circ} \mathrm{E}$ (Fig. 10). This mostly results from a significant southward velocity component east of $\sim 18^{\circ} \mathrm{E}$ (reaching to $-0.08 \mathrm{~m} / \mathrm{s}$ ), as apparent on the dotted-dashed line of Fig. 10 (of which the $22^{\circ} \mathrm{E}$ outlying point should probably be disregarded). This averaged southward component associated 
a

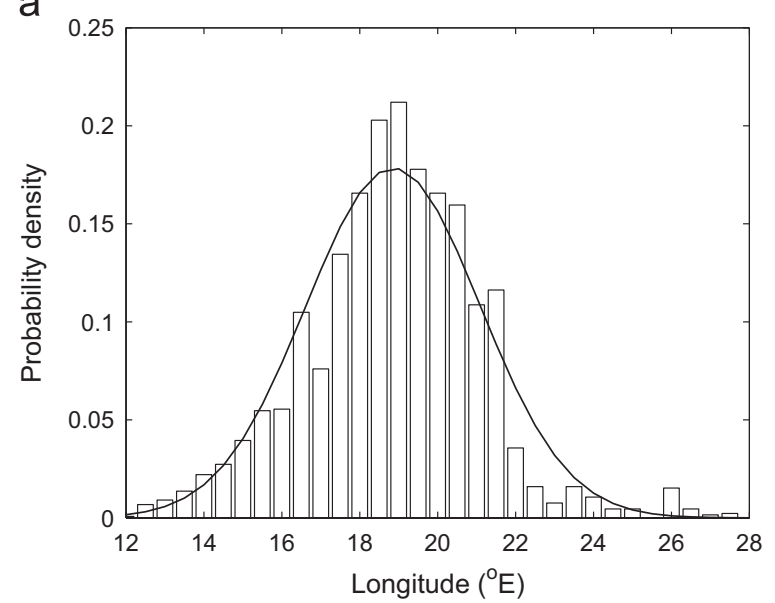

b

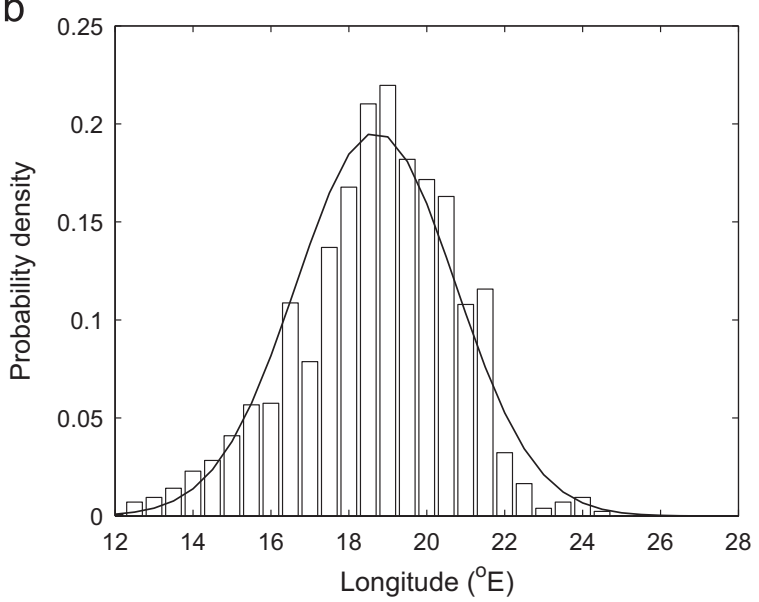

Fig. 9. Density of probability of the longitude of the retroflection point: (a) for the whole time series and (b) excluding the upstream retroflection event of $2000 / 2001$.

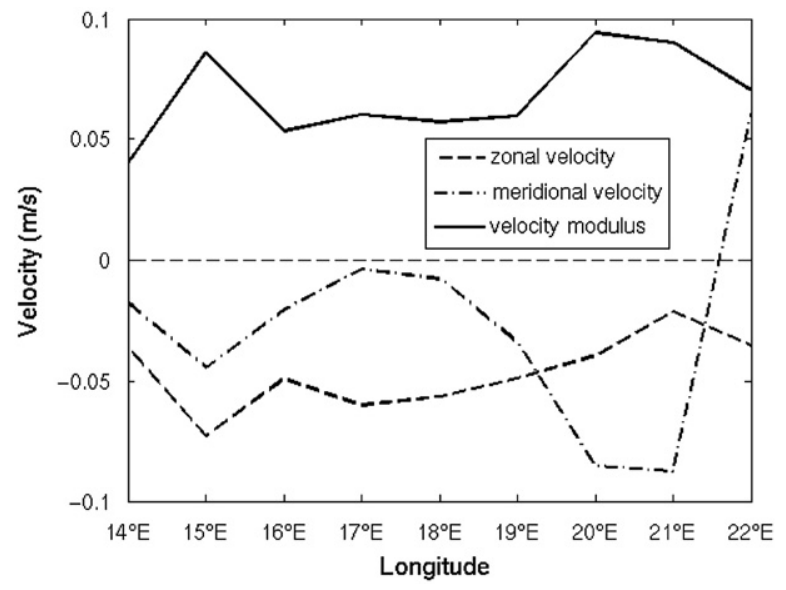

Fig. 10. Averaged zonal and meridional velocities (positive eastward and northward), and averaged velocity modulus of the retroflection point. The anomalous meridional velocity value at $22^{\circ} \mathrm{E}$ likely reflects instabilities of the retroflection latitude combined with a weak number of retroflection points available to compute the velocity estimate.

with the general northeast-southwest orientation of the retroflection positions east of $\sim 18^{\circ} \mathrm{E}$ (Fig. 6), enhances the velocity at these longitudes, causing its westward decrease trend.
Finally, west of $\sim 15^{\circ} \mathrm{E}$, the probability densities in excess of their Gaussian counterparts (Fig. 9) might reflect a slowing down of the retroflection point (Fig. 10) as the latter reaches the submarine bight formed by the Erica seamount, the Schmitt-Ott seamount, and the northeastern end of the Agulhas Ridge (Fig. 6). The higher probability density at $16^{\circ} 30^{\prime} \mathrm{E}$ (Fig. 9), and the coincident first slowing down of the retroflection westward progression (Fig. 10), might be an indication that the retroflection loop already feels the bathymetry at this longitude.

In order to further examine the extreme configurations of the Agulhas retroflection, we show in Fig. 11a and b the SSH fields averaged for the 5\% westernmost and 5\% easternmost retroflection points. Note that for the latter we excluded the period of the 2000/2001 upstream retroflection. The extreme western pattern (Fig. 11a) is very elongated, with the isoline $1.7 \mathrm{~m}$ representative of the current core in the instantaneous fields reaching to the afore-mentioned submarine bight. In this configuration the Agulhas Current separates from the continental slope at $\sim 20^{\circ} \mathrm{E}$ near the southernmost point of the African continental shelf. West of the Agulhas Bank and north of the detached Agulhas Current is a pronounced negative anomaly, a mark of the frequent presence of cyclones at this location. These structures were labelled "lee eddies" (Penven et al., 2001; Lutjeharms et al., 2003) to remind of their formation process downstream of the Agulhas Current detachment from the Agulhas Bank continental slope. This cyclonic pool is fed by cyclones propagating southwestward along the inshore side of the Agulhas Current, namely, Natal pulses formed in the upstream part of this current, and shear edge eddies from immediately east of the Agulhas Bank (Lutjeharms et al., 2003; Boebel et al., 2003). Cyclone formation was also observed to sometimes take place along the South African western continental slope as far north as $\sim 33^{\circ} \mathrm{S}$ (Morrow et al., 2004), and Baker-Yeboah et al. (2010) recently showed that this can occur as Agulhas rings approach the slope. This could be an additional source of cyclonic vorticity for the region west of the Agulhas Bank. Fig. 11a suggests that the lee eddies present there might, through advection, contribute to the westward elongation of the retroflection pattern, while the bathymetric obstacles at $13^{\circ} \mathrm{E}-16^{\circ} \mathrm{E}$, on the contrary, likely limit the westward progression of the extreme protrusions.

In the extreme eastern retroflection pattern (Fig. 11b), the Agulhas Current detaches southward from the slope at the southeastern corner of the Agulhas Bank, an observation which corroborates the idea of a link with the angle in the bank edge at $22^{\circ}$ E. Boebel et al. (2003) and Lutjeharms et al. (2003) showed that, when Natal pulses or shear edge eddies propagate southward along the shelf break past the Agulhas Bank, it may so happen that the induced southward shift of the Agulhas Current joins with the northward stretching of an Agulhas Return Current meander, causing the occlusion of the retroflection and the shedding of a ring. Lutjeharms et al. (2003) described such an event (their Fig. 8b) during which the retroflection retracted to $22^{\circ} \mathrm{E}$, in a manner representative of the extreme eastern pattern of Fig. 11b. Such a contribution of the Natal pulses and shear-edge eddies to the detachment of Agulhas rings was also underlined by van Leeuwen et al. (2000). After a ring has detached, in a configuration similar to that of Fig. 11b, the presence of a cyclone against the southern edge of the Agulhas Bank likely favours a southwestward orientation of the Agulhas Current downstream of its detachment location and, as a result, of the retroflection point. Returning to Fig. 10, the general westward deceleration is not monotonic, displaying two south(west)ward accelerations domains. One, at $20^{\circ} \mathrm{E}-22^{\circ} \mathrm{E}$, might reflect the effect of the cyclones adjacent to the southern border of the Agulhas Bank, that has just been described from Fig. 11b. The other acceleration domain, at $15^{\circ} \mathrm{E}-16^{\circ} \mathrm{E}$, necessarily referring to the elongated configuration of 
a

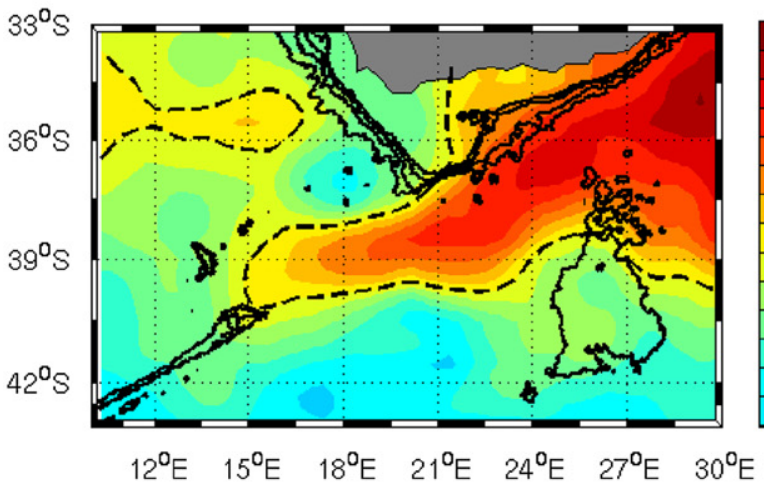

b

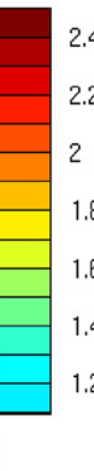

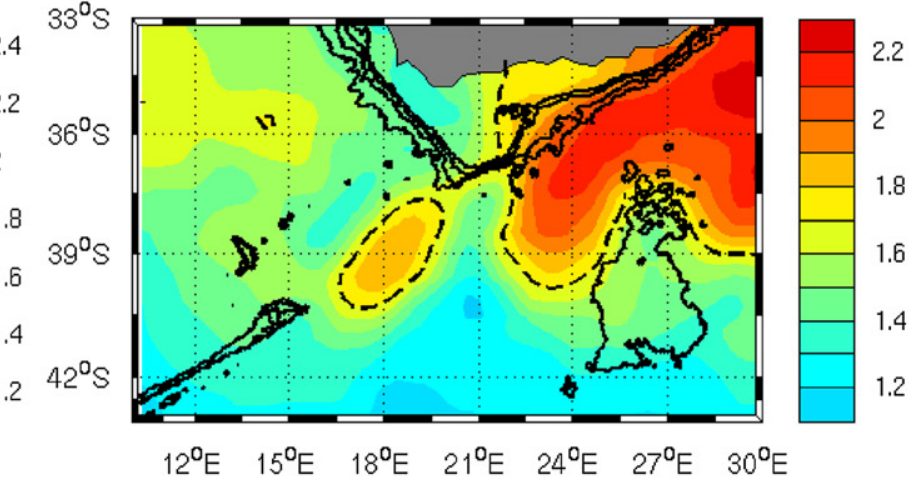

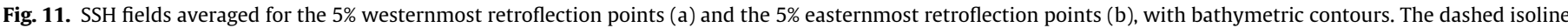
marks the value $1.7 \mathrm{~m}$ representative of the current core in the weekly fields.

Fig. 11a, could come from the above-mentioned advective effect of the cyclonic lee eddies adjacent to the detached Agulhas Current on its northern side. The lee eddies signature is also present in Fig. 11b, this time detached from the coast and adjacent to the newly formed Agulhas ring, a suggestion of dipole-like propagations of Agulhas rings and lee eddies. A southwestward initial detachment of the cyclonic lee eddies from the coast, as observed here by comparing Fig. 11a and b, was underlined by Morrow et al. (2004) from altimetric data, and by Richardson (2007) from trajectories of surface drifters and subsurface floats.

\section{The pulsation signal: Indications of influences by neighbouring cyclones and seamounts, and relation to Agulhas ring shedding}

A spectral analysis of the time series of the retroflection longitude (Fig. 12a) reveals a peak at 5 year $^{-1}$, as was expected from the well-defined seesaw signal of the retroflection pulsation in Fig. 8. Significant energy is also present at lower frequencies, although the spectrum does not resolve the associated components. High energy also shows in the upper part of the spectrum, particularly evidenced in its "variance preserving" form (Fig. 12b). As the longitude time series is strongly marked by the upstream retroflection event of 2000-2001, we recomputed the spectrum for the period before October 18,2000 , when the event started. This new spectrum (dashed curves in Fig. 12) is likely more representative of a typical behaviour of the retroflection. It no longer exhibits some peaks (at 8 year $^{-1}$ and 13-14 year ${ }^{-1}$ ) likely associated with the 2000-2001 event. The 5 year $^{-1}$ peak stands out more clearly, and the importance of a secondary peak at 12 year $^{-1}$ is more obvious than in the total spectrum, particularly in the "variance preserving" display. The latter peak is probably not associated with a distinct phenomenon in the retroflection behaviour, but with the sawtooth-like shape of the pulsations, generally characterized by slow westward motions and instantaneous eastward shifts. Such asymmetric oscillations are indeed composed of a main Fourier component and its slightly phase-shifted first harmonic. The second peak in Fig. 12 has not exactly the double frequency of the main one, probably because of finite frequency widths of both.

While the spectra of Fig. 12 provide us with the general energy distribution, they are of limited use when analysing the details of the various frequency domains. First considering the retroflection pulse-like behaviour, the 5 year $^{-1}$ spectral peak appeared sufficiently narrow and the seesaw shape of the time series strong enough to carry out a crest-to-trough analysis on the longitude time series. This consists in identifying the individual
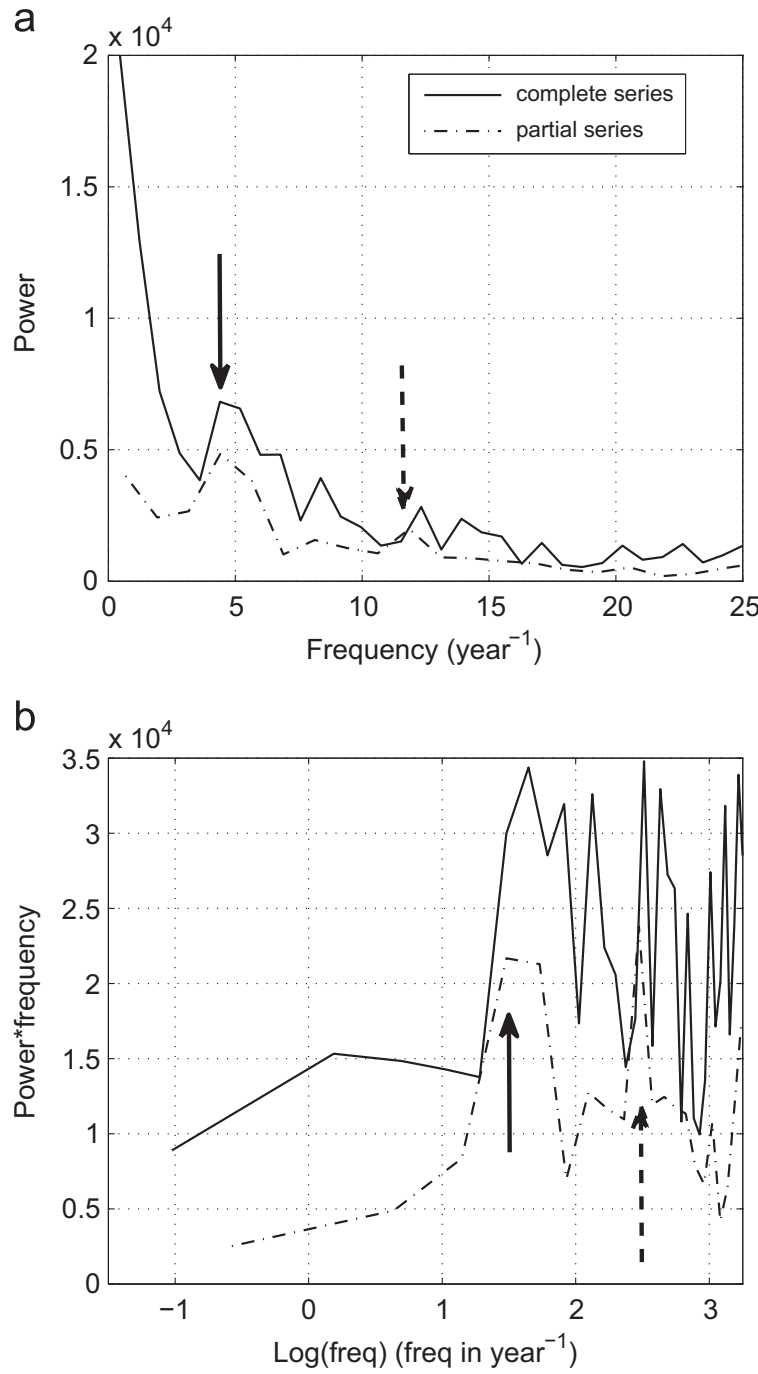

Fig. 12. (a) Power spectra of complete and partial (before 18 October 2000) time series of the retroflection point longitude. (b) Variance preserving spectra of the same time series. Continuous (discontinuous) arrows show the 5 year $^{-1}$ (12 year $^{-1}$ ) frequencies in both panels.

pulsations from the successive maxima and minima of the retroflection longitude. Such analysis led us to number 124 pulsations over the studied period. While some of these correspond to the idealized scheme of a monotonic westward 

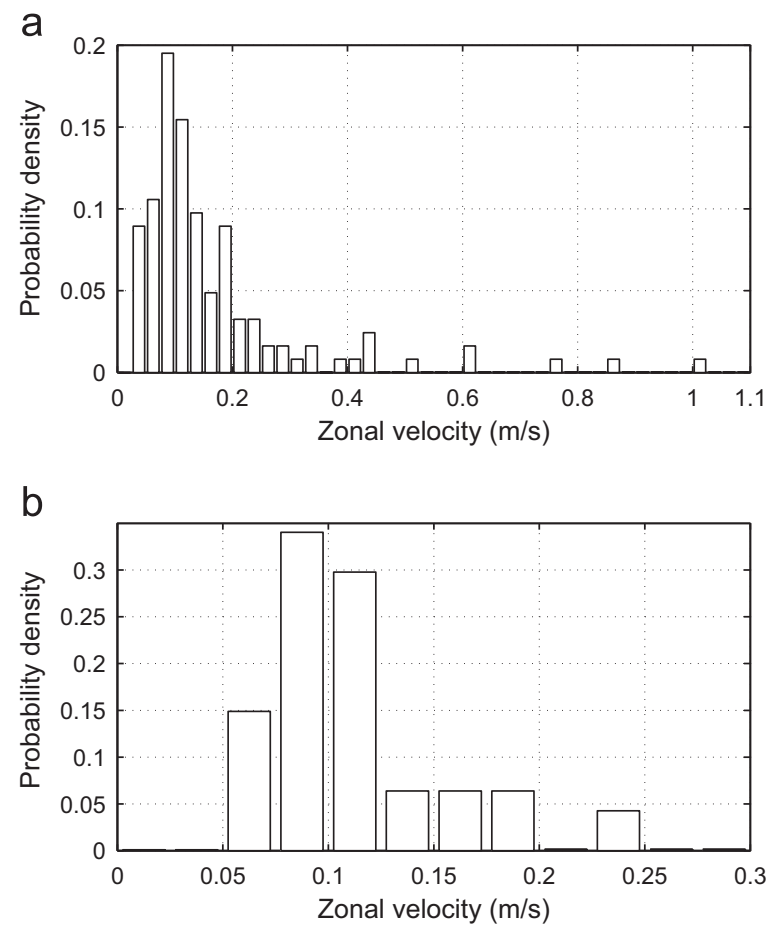

Fig. 13. Distribution of westward velocities of the retroflection point deduced from the crest-to-trough analysis: (a) for the 124 pulses of the study period and (b) only retaining the 41 pulses whose westward motions lasted more than 4 weeks.

progression of the retroflection followed by a rapid eastward shift (Lutjeharms and van Ballegooyen, 1988a), others are different (Fig. 8): One sort, characterized by intense and rapid variations of the retroflection longitude, result from the already mentioned re-absorption of a part or totality of a previously detached ring. Others are caused by weak and temporary recoils of the retroflection westward motion. In order to characterize the typical retroflection behaviour, we suppressed these particular variations of the retroflection longitude in some analyses by only considering the pulsations whose westward progressions last more than 4 weeks.

The nearly instantaneous eastward shifts of the Agulhas retroflection are poorly sampled by the 1 -week time step of the $\mathrm{SSH}$ fields, but the information provided by the crest-to-trough treatment on the western progressions is more realistic. These were found to last 25.7 days on average, with a widespread distribution (not shown). The distribution of associated westward velocities computed between the easternmost (crests) and westernmost (troughs) points of each pulsation is displayed in Fig. 13a. Despite a pronounced peak around $0.1 \mathrm{~m} / \mathrm{s}$, the averaged velocity associated with this histogram has a very high value of $0.183 \mathrm{~m} / \mathrm{s}$ (15.6 km/day), a consequence of isolated anomalous values reaching up to $1 \mathrm{~m} / \mathrm{s}$. Such westward jumps of the retroflection point result from temporary adjunctions of nearby eddies to the retroflection. Only retaining the westward progressions of more than 4 weeks, we filtered out these short pulsations (Fig. 13b) and obtained an averaged westward velocity of $0.11 \mathrm{~m} / \mathrm{s}(9.5 \mathrm{~km} /$ day $)$ more comparable to the $12 \mathrm{~km} /$ day average value found by Lutjeharms and van Ballegooyen (1988a, b), and the $7 \mathrm{~km} /$ day estimate of Feron and de Ruijter (1992).

\subsection{How the retroflection approaches the bathymetry}

The locations of the retroflection points on the dates of the eddy sheddings (Fig. 7), though not all close to the seamounts at $14^{\circ} \mathrm{E}-15^{\circ} \mathrm{E}$, look like they were limited westward by these obstacles. We also mentioned a slowing down of the westward motion of the retroflection point at $14^{\circ} \mathrm{E}-15^{\circ} \mathrm{E}$, that might reflect a bathymetric effect on the most pronounced westward progressions of the retroflection. Direct velocity measurements near $30^{\circ} \mathrm{E}$ in Beal (2009) show that the Agulhas Current, though clearly surface intensified, has velocities still reaching $0.15 \mathrm{~m} / \mathrm{s}$ at $1500 \mathrm{~m}$ depth, and between 0.05 and $0.10 \mathrm{~m} / \mathrm{s}$ at $2000 \mathrm{~m}$. Assuming that the current keeps such velocities farther downstream at its retroflection, the westward progressions of the retroflection point reaching the vicinity of the seamounts will likely be influenced by these obstacles, all of which culminate above $2000 \mathrm{~m}$ (reaching up to $1304 \mathrm{~m}$ for the Schmitt-Ott seamount, and $1285 \mathrm{~m}$ for the Erica seamount). This does not mean that these bathymetric obstacles are in any way a cause for the Agulhas Current retroflecting, or the shedding of rings, as these sometimes occur far east of the seamounts, and the general behaviour of the retroflection has been reproduced in modelling studies without any bathymetric effect. But for those pulsations that are driven to longitudes $14^{\circ} \mathrm{E}-17^{\circ} \mathrm{E}$ by their own dynamics or external forcing, the role of the seamounts might be to slow down the westernmost part of the progression of the retroflection point (as suggested in Fig. 10 at $14^{\circ} \mathrm{E}-15^{\circ} \mathrm{E}$ ), thus giving more time for the ring detachment process to be completed at these longitudes.

In order to further analyse how the retroflection point approaches these seamounts, we selected the retroflection pulsations whose westward progression lasted more than 4 weeks, and ended west of $18^{\circ} \mathrm{E}$. We identified 41 such pulsations, that is, one-third of the total number yet spanning $43 \%$ of the sampling time. The westernmost points of these pulsations (Fig. 14) have positions which bear a resemblance to those in the western part of the ensemble of retroflection points at the eddy shedding dates (Fig. 7). The locations displayed in Fig. 14, however, are not all recognized in Fig. 7, as the eddy shedding events do not necessarily occur at the pulsations westernmost positions. Fig. 14 shows that the retroflection pulsations which terminate farther westward, also generally terminate farther northward, than those of more limited extent. This led us to group the westernmost retroflection positions in two families, depending on whether they are located west or east of $16^{\circ} \mathrm{E}$. The western family (in blue in the figure) corresponds to those westward motions which end in the afore-mentioned submarine bight to the north of the Agulhas Ridge, whereas the eastern family (in red) corresponds to westward motions ending in front of, or close to, the northeastern tip of the ridge. The averaged westward trajectories of the two families are close to one another east of $18^{\circ} \mathrm{E}$, and diverge west of this longitude with the western family ending about one degree north of the eastern one.

The averaged SSH configurations for the two families (Fig. 15) suggest that the position of the cyclonic "lee eddy" to the north of the retroflection might have an influence as for which configuration (western or eastern) it will take. The cyclone is indeed detached from the continental slope in the eastern configuration, seemingly pushing the retroflection southward toward the northeastern tip of the Agulhas Ridge. In the western configuration, it is still located against the side of the Agulhas Bank, and its possible advective effect on the adjacent tongue of high SSH values would drive the latter toward the submarine bight formed by the seamounts.

De Ruijter et al. (1999) listed the main factors that control the retroflection of the Agulhas Current. Inertia and the $\beta$ effect, which force the current into the open ocean and cause its eastward turn, were shown in several numerical modelling studies to be the basic processes underlying the retroflection. The latter could also be affected, through a vortex stretching effect, by the southward rise of isopycnals which prevails at these 


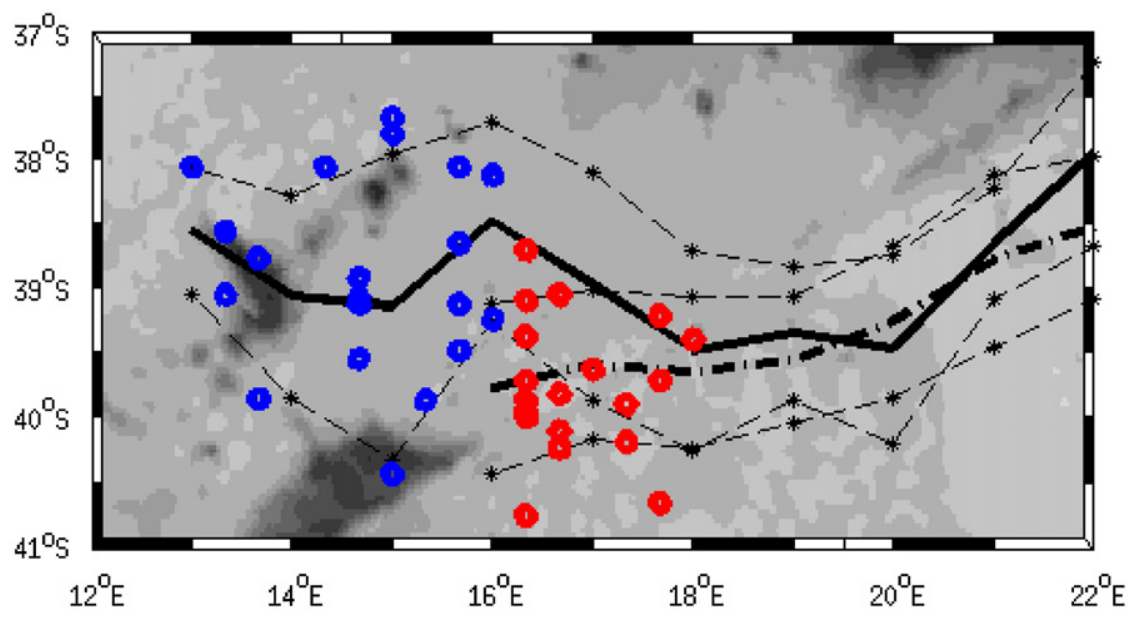

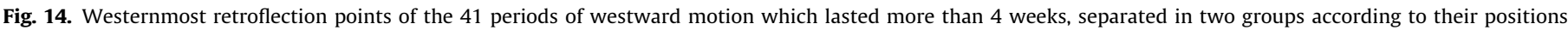

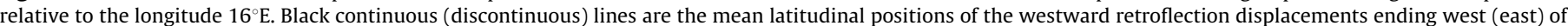
$16^{\circ} \mathrm{E}$.

a

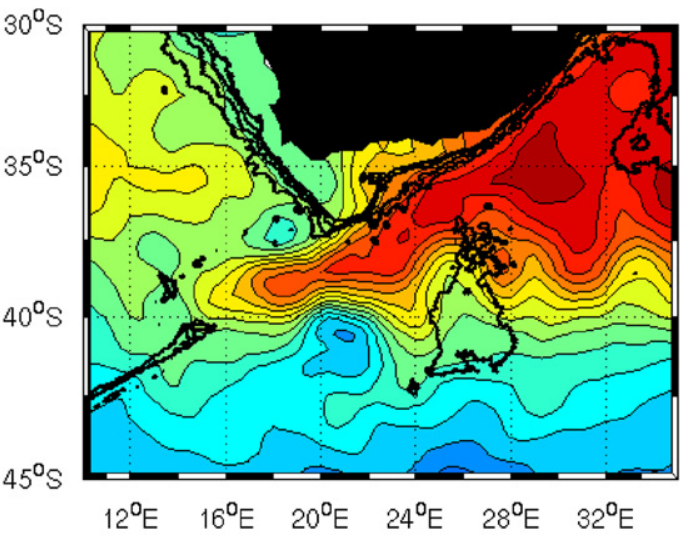

$\mathrm{b}$

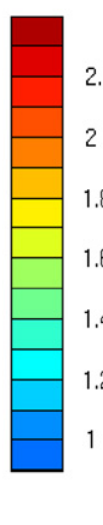

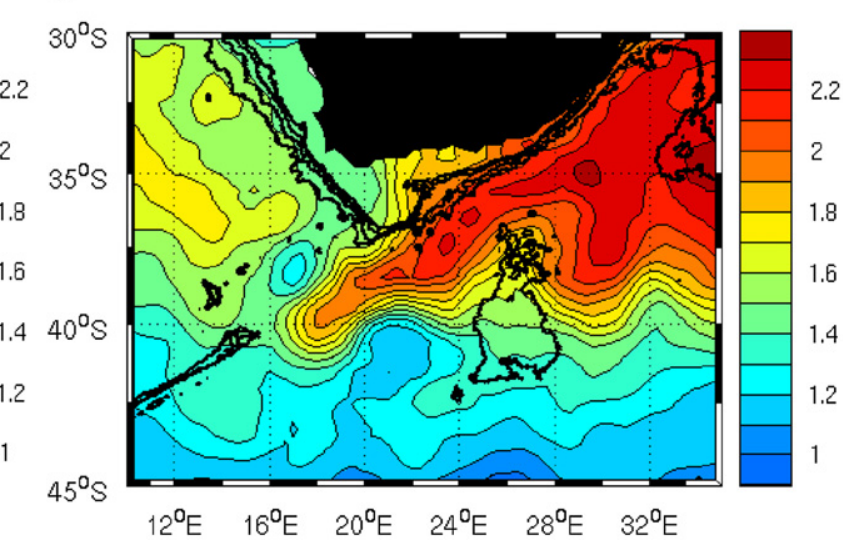

Fig. 15. Averaged SSH fields of the western (a) and eastern (b) families of extreme retroflection points displayed in Fig. 14.

latitudes. Summarizing the above inferences from Figs. 9, 10, 11 and 14 , we suggest that, added to these basic causes, are more local influences by the cyclones adjacent to the Agulhas Current, and by the seamounts at $14^{\circ} \mathrm{E}-15^{\circ} \mathrm{E}$, for the retroflection pulsations which reach such longitudes.

In situations when the Agulhas Current detaches from the coast near $22^{\circ} \mathrm{E}$ (Fig. $11 \mathrm{~b}$ ), we suggested above that the cyclones present south of the Agulhas Bank and adjacent to the Agulhas Current contribute to enhance the southward velocity of the retroflection point at $19^{\circ} \mathrm{E}-21^{\circ} \mathrm{E}$ (Fig. 10). In situations when the retroflection protrudes westward beyond the southwestern corner of the Agulhas Bank (Fig. 15), mutual interaction also certainly occurs between the detached Agulhas Current and the adjacent lee eddies frequently present west of the bank. Like the Agulhas Current, the cyclonic lee eddies have their own dynamics to which they certainly at least partly respond. They were shown to propagate southwestward away from the continental slope (Morrow et al., 2004), and do so at a rate which is not necessarily correlated with that of the retroflection pulsations. This apparently leads to variable effects. In situations of westward elongated retroflection, a lee eddy close to the continental slope (Fig. 15a) seem to orientate the retroflection point westward to the opening of the submarine bight formed by the seamounts at $14^{\circ} \mathrm{E}-15^{\circ} \mathrm{E}$. On the other hand, a lee eddy detached from the continental slope (Fig. 15b) and itself near the opening of the submarine bight, likely pushes the tip of the retroflection southward toward the eastern end of the Agulhas Ridge. These two situations result in the two families of extreme retroflection points displayed in Fig. 14. Distinguishing these two extreme retroflection patterns may be of importance, as the detached rings will likely behave differently. Those separating from the western family might be prone to stalling in the bathymetric bight before eventually crossing it westward. Those formed close to the end of the ridge might subdivide on encountering it. Examples of both behaviours are described in Arhan et al. (1999).

\subsection{Agulhas ring shedding}

The 73 definitive and 3 temporary eddy separations from the retroflection identified over the 12.7-year time series are represented in Fig. 8 on the longitude plot of the retroflection point. They correspond to an annual average of 5.8 definitive shedding events separated by $63 \pm 31$ days. This frequency slightly exceeds that of the spectral peak in Fig. 12, because of the higher frequencies also present in the spectrum. Although most separation events coincide with westward extremes of the retroflection position, a few of them were delayed relative to the extreme. This sometimes occurred when the retroflection was unstable and retreated prior to a detachment. In other instances, 
Table 1

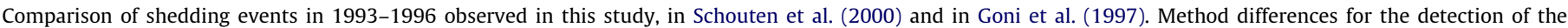
shedding events in the three studies are described in the text.

\begin{tabular}{|c|c|c|c|c|c|}
\hline & $\begin{array}{l}\text { Definitive } \\
\text { shedding events } \\
\text { (this study) }\end{array}$ & $\begin{array}{l}\text { Definitive and } \\
\text { temporary shedding } \\
\text { events (this study) }\end{array}$ & $\begin{array}{l}\text { No. of shedding } \\
\text { events observed by } \\
\text { Schouten et al. (2000) }\end{array}$ & $\begin{array}{l}\text { Individual events } \\
\text { recognized in } \\
\text { Schouten et al. (2000) } \\
\text { and this study }\end{array}$ & $\begin{array}{l}\text { No. of shedding } \\
\text { events observed by } \\
\text { Goni et al. (1997) }\end{array}$ \\
\hline 1993 & 5 & 6 & 4 & 3 & 5 \\
\hline 1994 & 6 & 6 & 6 & 4 & 4 \\
\hline 1995 & 6 & 6 & 5 & 4 & 6 \\
\hline 1996 & 5 & 6 & 5 & 2 & \\
\hline $\begin{array}{l}\text { No. of shedding events per year } \\
\text { (1993-1996) }\end{array}$ & 5.5 & 6 & 5 & & 5 \\
\hline
\end{tabular}

it was associated with separations lasting several weeks, first through the loss of small water parcels, causing a first retreat of the retroflection, and followed by a major eddy detachment.

The number of shedding events per year compares well with previous estimates also obtained from altimeter data. Feron and de Ruijter (1992) inferred the spawning of rings from drops in the correlation between successive fields of SSH anomalies from the GEOSAT altimeter. They counted 18 events between November 1986 and September 1989, that is, 6.2 per year. Goni et al. (1997) used TOPEX/Poseidon SSH anomalies to identify rings that crossed satellite ground tracks located immediately west of the retroflection region. They observed 5 crossings per year during the 3-year period 1993-1995. Schouten et al. (2000), using the same method as Feron and de Ruijter (1992) to detect ring spawning from TOPEX/Poseidon data, also found an average of 5 per year over the 4-year period 1993-1996. Table 1 compares the numbers of shedding events found in this study on a yearly basis in 1993-1996 with those of Schouten et al. (2000) and Goni et al. (1997) who also used TOPEX/Poseidon data. Divergences by up to 2 events per year between the three studies certainly reflect the use of different methods to detect the ring formation events. Goni et al. (1997) noted that rings might, on occasion, form out of the range covered by the TOPEX/Poseidon ground track they analysed, a possible reason for their finding a slightly lower ring formation rate than in this study. Our finding a higher rate than the two other studies might also result from the use of (absolute) SSH data in this study, and SSH anomalies in the two others. Feron and de Ruijter (1992) pointed out the difficulty to tell eddies from meanders in the SSH anomaly signal and, as a consequence, to extract the ring shedding process from such data.

The large standard deviation of the time intervals between successive ring shedding events ( 31 days) agrees with previous observations regarding the time variability of the formation of rings. Goni et al. (1997) and Schouten et al. (2000) found between 4 and 6 rings formed each year between 1993 and 1996 (Table 1), and Feron and de Ruijter (1992) identified between 4 and 8 events per year during the period 1986-1989. However, the different methods and data used in this study and previous ones again result in divergences when considering the recognition of individual events and intervening time intervals. We only identified 13 of the 20 ring formations reported by Schouten et al. (2000) (Table 1), and only recognized one of the three periods of more than 4 months without any shedding event that those authors reported for 1993-1996. We identified other long periods without any separation event, four of them exceeding 4 months (Fig. 8), and the largest one being associated with the early retroflection of 2000/2001. This one lasted nearly 6 months, as already observed by de Ruijter et al. (2004).

Finally, taking advantage of this long time series of Agulhas ring shedding events, we looked for a possible seasonality of the process of eddy separation. No preferential season was observed, in accordance with the finding of Goni et al. (1997) that the shedding of rings was "neither continuous nor periodic" in the altimeter data of 1993-1996.

\section{Seasonal and inter-annual variability of the Agulhas retroflection}

While the eddy shedding process does not show any obvious seasonality, it might not be so for the Agulhas Current retroflection itself. Actually, the question of the seasonality of the retroflection has been at debate for a long time. Considering a possible seasonality of the westward extent of the retroflection, it may be traced back to Veronis' (1973) theory, which predicted that the current should separate from the continental slope farther west during the austral summer, when a weaker flow is expected. Using a free inertial jet model, Lutjeharms and van Ballegooyen (1984) found a link between the volume transport and westward penetration of the current. From satellite infrared images in the period 1978-1982, they also showed an increased westward protrusion during summer, but considering the high percentage of cloud cover, they were cautious regarding a possible generalization of their observations to a regular seasonal regime.

Contradicting the view of a reduced Agulhas Current transport during summer, Ffield et al. (1997) using altimeter and wind data found a stronger southward Agulhas Current at the end of austral summer (March) and a minimum in early austral winter (June). Matano et al. (1998), also using altimeter data, observed that waves propagating from the Indian Ocean that could provide the large scale seasonal adjustment of the Agulhas retroflection are blocked by the Madagascar Ridge, so that the effect of local winds might prevail to determine the seasonal variations of the current. They were led to propose a retroflection regime which matches the Agulhas Current variations of Ffield et al. (1997), namely, extended westward penetration to about $15^{\circ} \mathrm{E}$ in winter, and significant partial branching at $\sim 25^{\circ} \mathrm{E}$ in summer.

A seasonal signal in the time series of the retroflection longitude might have two causes. One is naturally a real seasonal dependence of the retroflection point. Another one might be a seasonally dependent SSH signature of the retroflection which, through our use of a constant SSH criterion to locate it, might produce an artificial time dependent signal. We verified that the SSH-geostrophic velocity relation was not subject to any seasonality, so that only a real seasonality of the longitude of the retroflection could explain an annual signal.

As a first step, computing the monthly means of the retroflection longitude did not reveal any significant annual cycle. This seemed to corroborate the inference drawn from the comparison of the total and partial spectra in Fig. 12, that the low frequency energy is mostly attributable to the 2000-2001 event, rather than 
to a periodic signal. We found, however, a first hint to seasonality of the retroflection longitude on comparing Fig. 11, which displays the 5 percent westernmost and easternmost mean retroflection configurations with Fig. 6 of Lutjeharms and van Ballegooyen (1984), where the authors showed composites of Agulhas Retroflection paths in winter and summer, deduced from infrared satellite images. Their figure for the winter months suggests a detachment of the Agulhas Current from the continental slope near $22^{\circ} \mathrm{E}$, in a configuration reminding that of the 5 percent easternmost retroflection points in Fig. 11b. Their figure for the summer months, on the other hand, suggests a detachment at the southern end of the Agulhas Bank $\left(\sim 20^{\circ} \mathrm{E}\right)$, closer to the 5 percent westernmost configuration in Fig. 11a. For a confirmation of such season dependency of the retroflection longitude, we show in Fig. 16 the histograms of the dates at which the western and eastern longitude extremes were observed. While western retroflection extremes occur all year round, their probability is clearly highest in austral summer and fall, and lowest in winter. The dates of the eastern extremes exhibit an even more contrasted behaviour, with very few occurrences in summer, and numerous observations in winter.

With such a hint for seasonality, we carried out a singular spectrum analysis (SSA) on the longitude time series, a method that can be used to identify periodic signals modulated in phase or amplitude. Such a technique offered the possibility to remove the 2000-2001 event from the time series without reducing its length. More generally, the SSA provides better accuracies and resolutions for low frequencies than a spectral analysis. For a detailed description of this tool, the reader may refer to Vautard and Ghil (1989), and Vautard et al. (1992). Basically, it rests on a matrix diagonalization technique, and decomposes the original signal into uncorrelated components which may correspond to tendencies, non-linear periodic signals, and noise. The method main parameter is the analysis window length $M$, which should exceed that of the highest period we look for. This parameter should not exceed $N / 5$, with $N$ being the length of the time series, and the periodic signals correctly resolved have periods between $M$ and $M / 5$. With in our case $N=658$ weeks, we arrived after some trials at a choice of $M=111$ weeks, which allowed us to detect periods up to slightly more than 2 years and down to 22 weeks. It was anticipated that such a window would allow detecting the 2000-2001 event and the annual periods, but would not reflect the retroflection pulsations.

\subsection{The low frequency signal}

The SSA provides eigenvectors sorted by decreasing order of explained variance, the periodic components being associated with vector pairs of comparable explained variance.

The application of the SSA to the longitude time series led to two pairs of principal vectors at low frequencies. The first one, of approximate period 2 years, is linked to the 2000-2001 event (Fig. 17a). The second one, of annual period, is similarly intensified on this event, but also present before and after it (Fig. 17b). A fifth vector contains the signal tendency (Fig. 17c), and a third noisy pair has a period of about 9 months (Fig. 17d). Altogether these 7 first eigenvectors accounts for 30.4 percent of the total variance.

Examining the reconstituted signal of the two first oscillating pairs (Fig. 17a and b) reveals several periods in the time series. Before week 200 (August 1996) and after week 500 (May 2002), the bi-annual signal (Fig. 17a) is nearly zero, and the annual signal has a relatively constant amplitude (Fig. 17b). From week 200 to week 350 (July 1999) the annual signal decreases and eventually vanishes (Fig. 17b), while the bi-annual signal increases (Fig. 17a). The increase of the bi-annual signal continues until week 430 (December 2000), the very date when the retroflection occurred east of the Agulhas Plateau. After this date, the bi-annual signal decreases until it vanishes around week 500. This peak of influence of the bi-annual signal centred on the 2000-2001 event is accompanied by a sudden new increase of the annual component, with a maximum of the latter also present on week 430 during the upstream retroflection event.

Such a phase coupling between the annual and bi-annual components during the upstream retroflection event reflects the enhancement of the eastward peak (crest) of the event, and its association with comparatively weak neighbouring westward troughs. The signal time asymmetry (rapid eastward shift followed by slow westward motion) is itself accounted for by the 9-month oscillation (Fig. 17d), which is in slight phase advance relative to the bi-annual and annual signals.

\subsection{The annual component of the retroflection longitude}

This component was found to account for 9.1 percent of the total variance. Now distinguishing the periods mentioned above, we observe (Fig. 18a) that from October 1992 to the end of 1997 the a

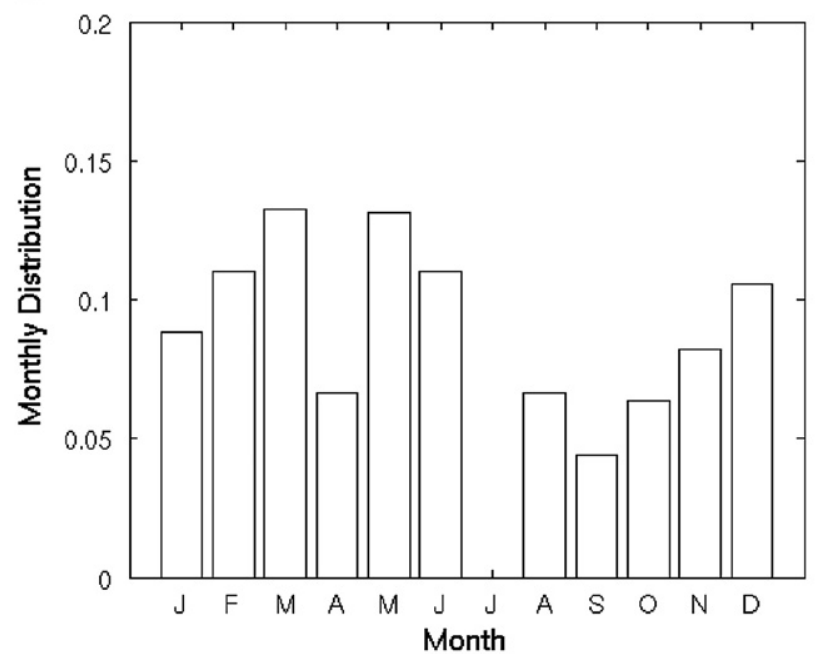

b

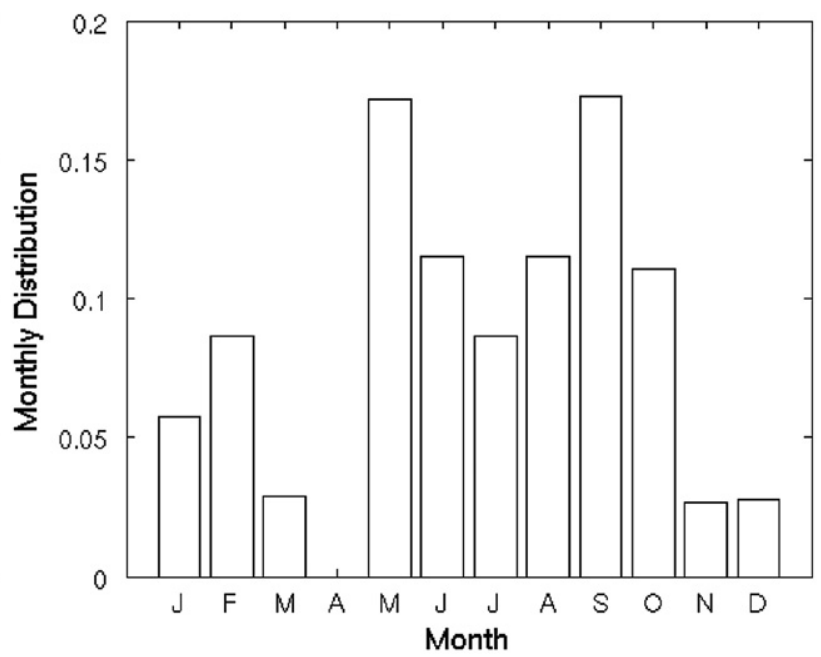

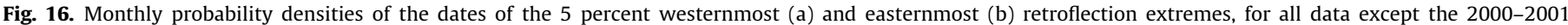
upstream retroflection cycle. 

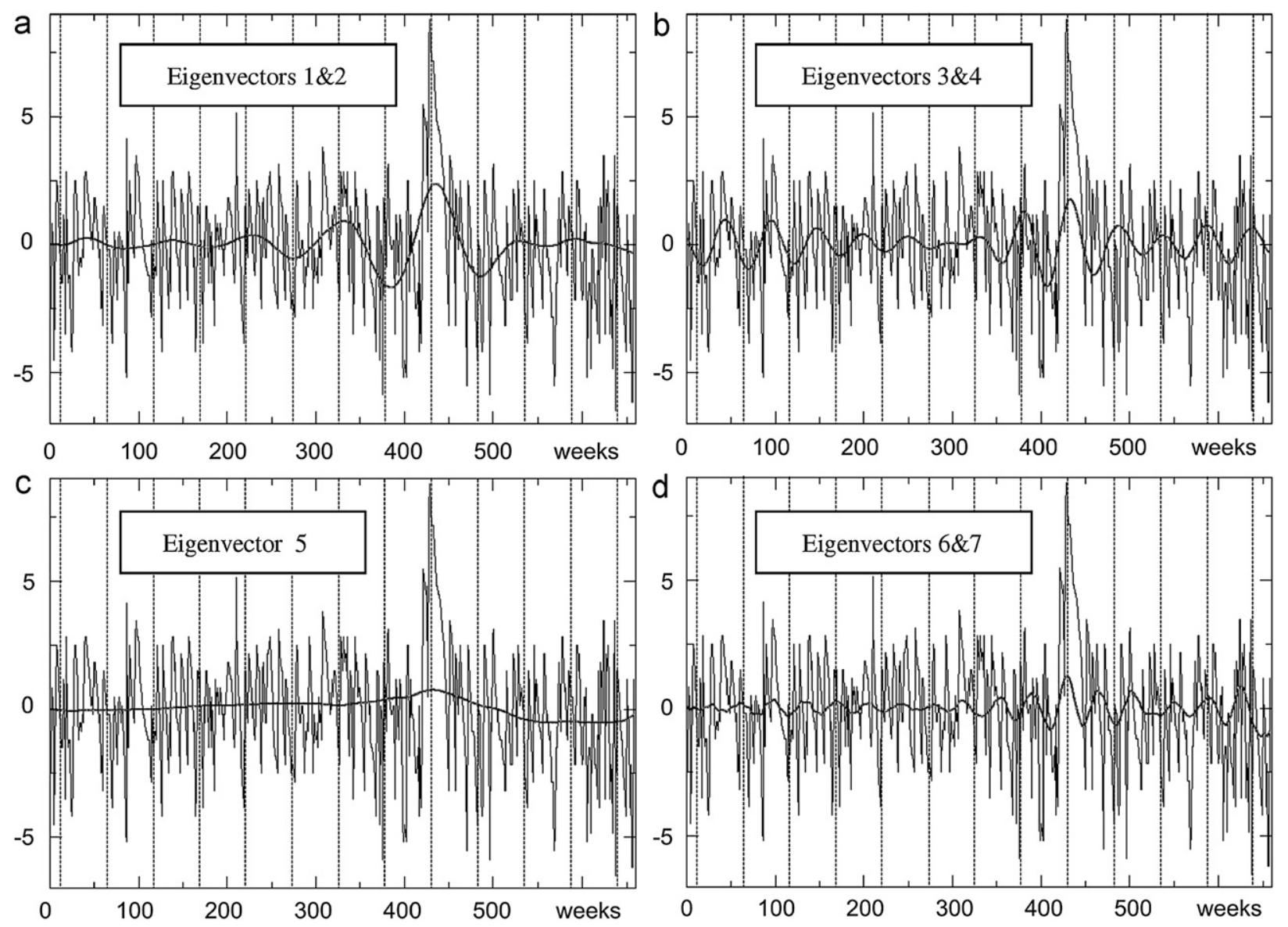

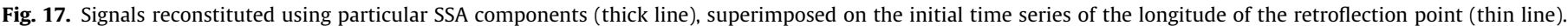

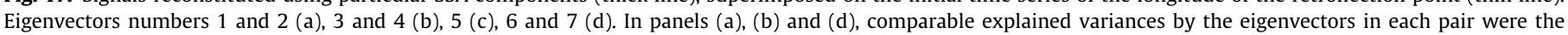
signatures of periodic signals. Stippled vertical lines mark the beginning of each year.

retroflection was clearly shifted westward during the austral summer and eastward during winter, in keeping with the observations of Lutjeharms and van Ballegooyen (1984) from infrared satellite images. However, following the 1998 attenuation, a larger amplitude of the signal occurs in 1999-2001, which is also characterized by a phase shift of $180^{\circ}$ relative to the preceding period. After 2001 the amplitude stabilizes and, although the phase stays in opposition to the pre-1998 period, it slowly drifts toward the initial phase. It appears, therefore, that a seasonal cycle of the retroflection does exist, yet had its phase perturbed and durably inverted during and following the 2000-2001 upstream retroflection. The comparable durations of the periods preceding and following this event explain why no seasonal variation was detected from the monthly averages computed from the whole time series. As a confirmation of this, Fig. 18b-d show that the longitude monthly averages, when computed on the above sub-periods, do exhibit annual variations comparable to those of the SSA reconstructed signals. The seasonal amplitudes range from $1^{\circ}$ to $1.3^{\circ}$ of longitude depending on the time period. These are quite significant variations if compared to the overall longitude standard deviation of $2.2^{\circ}$, or to the $2^{\circ}$ standard deviation obtained after removing the 2000-2001 event.

\section{Discussion}

The statistical analysis of the Agulhas Current retroflection carried out from its SSH signature over a 12.7-year period has provided detailed descriptions of the geographical probability distribution of the retroflection point, and of its time variations at periods up to about 2 years. Relating features of the probability distribution to velocity characteristics of the retroflection pulsations has led us to underline likely local contributions to the retroflection behaviour, by cyclonic eddies present north of the detached Agulhas Current, and by the seamounts at $14^{\circ} \mathrm{E}-15^{\circ} \mathrm{E}$ which might influence the westernmost Agulhas protrusions. We do not mean, of course, that these are dominant controlling factors for the behaviour of the retroflection. Previous theoretical and modelling studies have shown the role of upstream Agulhas Current characteristics and, originally, of the wind geographical distribution and variations in governing the retroflection via nonlinear dynamics. The retroflection pulses themselves were shown to be related to Natal pulses formed inshore of the northern Agulhas Current (van Leeuwen et al. (2000)) and to processes still farther upstream (Schouten et al., 2002). The combined influences of cyclones and seamounts here inferred from the SSH data are expected to only perturb the basic retroflection pulsations, by enhancing some westward protrusions to the vicinity of the seamounts where they (and the detached Agulhas rings) can be subject to bathymetric effects. Depending on whether the cyclonic lee eddies remain adjacent to the continental slope during the retroflection westward motion, or separate from it, there are indications that the Agulhas protrusion will reach its westernmost position in the submarine bight formed by the seamounts, or farther south in front of the Agulhas Ridge. Although not exceeding one latitudinal degree, the difference might be of importance for the Agulhas rings formed during these pulsations, as they will be faced with different bathymetric obstacles on their 
a

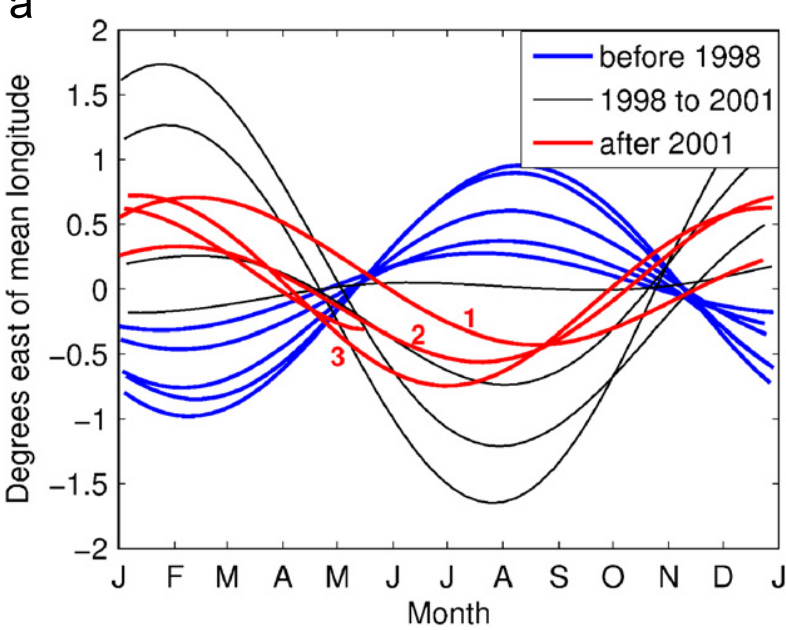

C

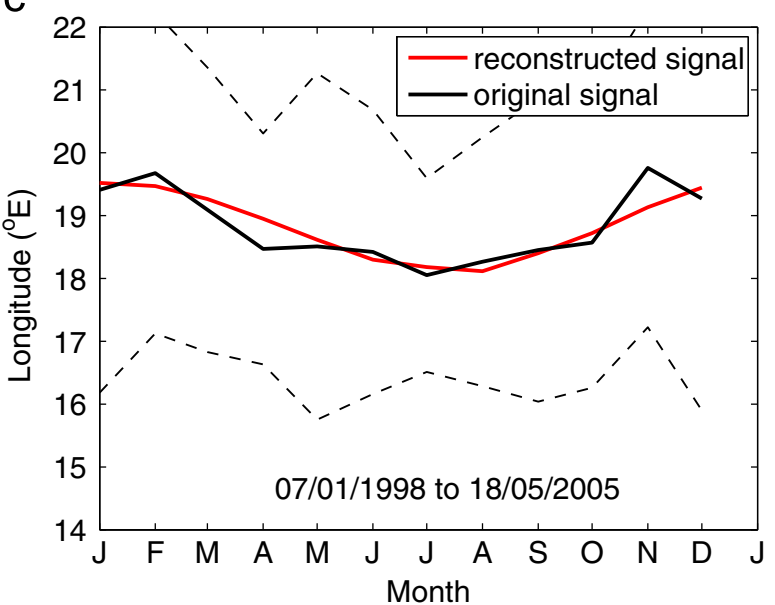

b

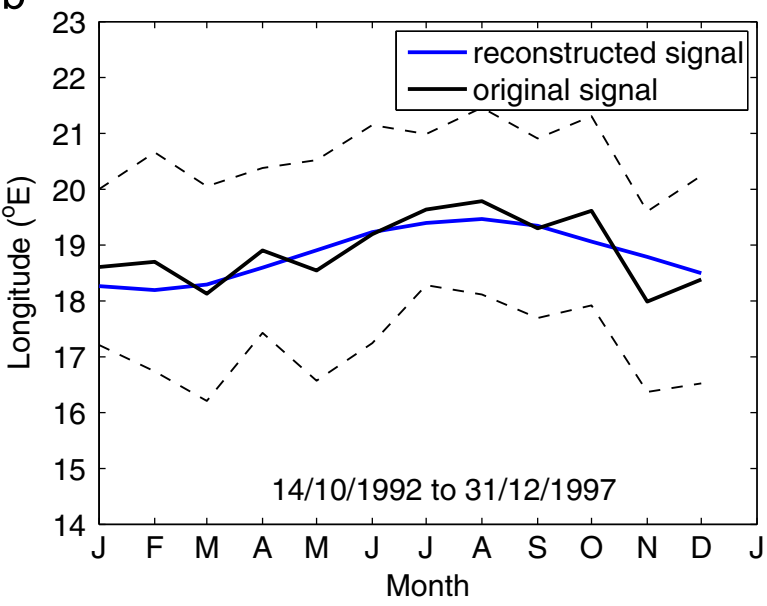

d

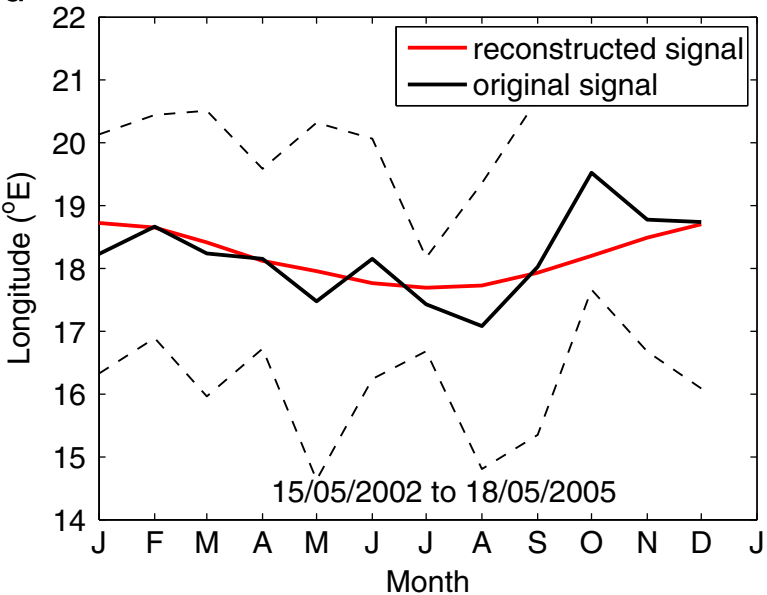

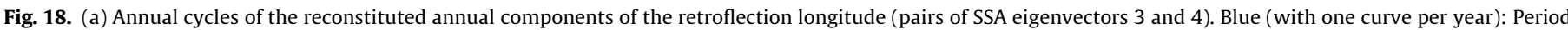

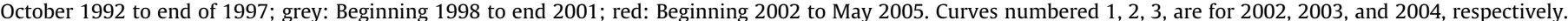

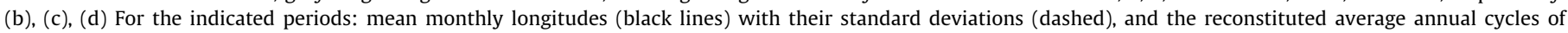

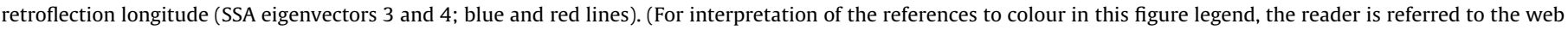
version of this article.)

way to the South Atlantic. Different effects may ensue (splitting, slowing down, stalling), as well as different northwestward routes that will expose them to different oceanic and atmospheric environments. This influence of the seamounts and Agulhas Ridge on the rings trajectories is described, also using the SSH data, in a separate article by the same authors (Dencausse et al., in preparation).

Our results on the retroflection pulsation and Agulhas ring shedding generally corroborate the results from previous studies, although differences were found in individual ring shedding events, due to different data (SSH or SSH anomalies) and the use of different methods to detect these events. At lower frequencies, the monthly averages of the retroflection longitude computed from the 12.7-year time series did not provide any indication of seasonality, but the SSA analysis provided evidence of a welldefined annual cycle from 1992 to 1997, corroborating the previously suggested regime of a westward (eastward) displaced retroflection during the austral summer (winter). A strong perturbation to this basic regime occurred during the upstream retroflection event of 2000-2001, which resulted in a phasing of the annual signal with the dominant low-frequency component, and a total phase inversion which prevented detecting the seasonality from just the monthly averages. It is uncertain whether the long-lasting phase shift resulted from the upstream retroflection itself, or whether inter-annual changes in the wind field caused the event and the phase shift, through changes in the Agulhas Current. The well-established seasonal regime observed before 1998, and the slow phase drift toward the former regime after 2001, plead in favour of a durable effect of the 2000-2001 event. As this event was particularly intense and long lasting, with a 6-month time gap before a return to more typical pulsation rates, other less pronounced upstream retroflections might not have such drastic effect on the phase of the annual component.

While this study has improved the characterization of the Agulhas retroflection pulses, some of the inferences drawn here from the statistical analysis of the retroflection positions are admittedly not firm conclusions, and would benefit from corroborations through different approaches or extended data sets. As an example, the mutual interaction of the cyclones and the retroflection tongue requires further inquiry, possibly through a joint analysis of the retroflection points and cyclone tracks. The deductions pertaining to the retroflection seasonality and its perturbations by upstream retroflections similarly would require confirmation through other occurrences of such events. 


\section{Acknowledgements}

This contribution to the CLIVAR/GoodHope programme was supported by the IFREMER programme "Circulation Océanique", by Institut National des Sciences de l'Univers (INSU), the CNRS, and by the Université de Bretagne Occidentale. G. Dencausse's contribution was done while a student at the Laboratoire de Physique des Océans, supported by a grant from the Ecole Normale Supérieure. We thank P. Penven for useful discussions. We are also thankful to three reviewers, whose comments helped improve the manuscript.

\section{References}

Arhan, M., Mercier, H., Lutjeharms, J.R.E., 1999. The disparate evolution of three Agulhas rings in the South Atlantic ocean. Journal of Geophysical Research 104, 20987-21005.

Baker-Yeboah, S., Flierl, G.R., Sutyrin, G.G., Zhang, Y., 2010. Transformation of an Agulhas eddy near the continental slope. Ocean Science 6, 143-159.

Beal, L.M., 2009. A time series of the Agulhas Undercurrent transport. Journal of Physical Oceanography 39, 2436-2450.

Boebel, O., Lutjeharms, J.R.E., Schmid, C., Zenk, W., Rossby, T., Barron, C., 2003. The Cape Cauldron: a regime of turbulent inter-ocean exchange. Deep-Sea Research II 50, 57-86.

Byrne, D.A., Gordon, A.L., Haxly, W.F., 1995. Agulhas eddies: a synoptic view using Geosat ERM data. Journal of Physical Oceanography 25, 902-917.

Dencausse, G., Arhan, M., Speich, S., in preparation. Routes of Agulhas rings in the southeastern Cape Basin. Deep-Sea Research I 57, doi:10.1016/j.dsr. 2010.07.008.

De Ruijter, W.P.M., Biastoch, A., Drijfhout, S.S., Lutjeharms, J.R.E., Matano, R.P. Pichevin, T., van Leeuwen, P.J., Weijer, W., 1999. Indian-Atlantic interocean exchange: dynamics, estimation and impact. Journal of Geophysical Research 104, 20885-20910.

De Ruijter, W.P.M., van Aken, H.M., Beier, E.J., Lutjeharms, J.R.E., Matano, R.P., Schouten, M.V., 2004. Eddies and dipoles around South Madagascar: formation, pathways and large scale impact. Deep-Sea Research I 51, 383-400.

Ducet, N., Le Traon, P.Y., Reverdin, G., 2000. Global high resolution mapping of ocean circulation from TOPEX/POSEIDON and ERS-1 and -2 . Journal of Geophysical Research 105, 19477-19498.

Duncan, C.P., 1968. An eddy in the subtropical convergence southwest of South Africa. Journal of Geophysical Research 73, 531-534.

Feron, C.V., de Ruijter, W.P.M., 1992. Ring shedding in the Agulhas Current System. Journal of Geophysical Research 97, 9467-9477.

Ffield, A., Toole, J., Wilson, D., 1997. Seasonal circulation in the South Indian Ocean Geophysical Research Letters 24, 2773-2776.

Goni, G.J., Garzoli, S.L., Roubicek, A.J., Olson, D.B., Brown, O.B., 1997. Agulhas ring dynamics from TOPEX/POSEIDON satellite altimeter data. Journal of Marine Research 55, 861-883.

Gordon, A.L., Lutjeharms, J.R.E., Gründlingh, M.L., 1987. Stratification and circulation at the Agulhas retroflection. Deep-Sea Research 34, 565-599.
Gründlingh, M.L., 1978. Drift of satellite-tracked buoy in the southern Agulhas Current and Agulhas Return Current. Deep-Sea Research 25, 1209-1224.

Harris, T.F.W., van Foreest, D., 1978. The Agulhas Current in March 1969. Deep-Sea Research 25, 549-561.

Harris, T.F.W., Legeckis, R., van Foreest, D., 1978. Satellite infra-red images in the Agulhas Current System. Deep-Sea Research 25, 543-548.

Le Traon, P.Y., Nadal, F., Ducet, N., 1998. An improved mapping method of multisatellite altimeter data. Journal of Atmospheric and Oceanic Technology $15,522-534$.

Lutjeharms, J.R.E., 2006. The Agulhas Current. Springer-Verlag 329 pp.

Lutjeharms, J.R.E., Boebel, O., Rossby, H.T., 2003. Agulhas cyclones. Deep-Sea Research II 50, 13-34.

Lutjeharms, J.R.E., Gordon, A.L., 1987. Shedding of an Agulhas ring observed at sea. Nature 325, 138-140.

Lutjeharms, J.R.E., van Ballegooyen, R.C., 1984. Topographic control in the Agulhas Current system. Deep-Sea Research 31, 1321-1337.

Lutjeharms, J.R.E., van Ballegooyen, R.C., 1988a. The retroflection of the Agulhas Current. Journal of Physical Oceanography 18, 1570-1583.

Lutjeharms, J.R.E., van Ballegooyen, R.C., 1988b. Anomalous upstream retroflection in the Agulhas Current. Science 240, 1770-1772.

Matano, R.P., Simionato, C.G., de Ruijter, W.P., van Leeuwen, P.J., Strub, P.T., Chelton, D.B., Schlax, M.G., 1998. Seasonal variability in the Agulhas retroflection region. Geophysical Research Letters 25, 4361-4364.

Morrow, R., Birol, F., Griffin, D., Sudre, J., 2004. Divergent pathways of cyclonic and anti-cyclonic ocean eddies. Geophysical Research Letters 31, L24311. doi:10.1029/2004GL020974

Penven, P., Lutjeharms, J.R.E., Marchesiello, P., Roy, C., Weeks, S.J., 2001. Generation of cyclonic eddies by the Agulhas Current in the lee of the Agulhas Bank. Geophysical Research Letters 27, 1055-1058.

Quartly, G.D., Srokosz, M.A., 2002. SST observations of the Agulhas and East Madagascar retroflections by the TRMM Microwave Imager. Journal of Physical Oceanography 32, 1585-1592.

Richardson, P.L., 2007. Agulhas leakage into the Atlantic estimated with subsurface floats and subsurface drifters. Deep-Sea Research I 54, 1361-1389.

Rio, M.H., Hernandez, F., 2004. A mean dynamic topography computed over the world ocean from altimetry, in situ measurements, and geoïd model. Journal of Geophysical Research 109, C12032.

Schouten, M.W., de Ruijter, W.P.M., van Leeuwen, P.J., 2000. Translation, decay, and splitting of Agulhas rings in the southeastern Atlantic Ocean. Journal of Geophysical Research 105, 21913-21925.

Schouten, M.W., de Ruijter, W.P.M., van Leeuwen, P.J., 2002. Upstream control of Agulhas ring shedding. Journal of Geophysical Research 107). doi:10.1029/ 2001JC000804.

Van Leeuwen, P.J., de Ruijter, W.P.M., Lutjeharms, J.R.E., 2000. Natal pulses and the formation of Agulhas rings. Journal of Geophysical Research 105, 6425-6436.

Vautard, R., Ghil, M., 1989. Singular spectrum analysis in nonlinear dynamics, with applications to paleoclimatic time-series. Physica D 35, 395-424.

Vautard, R., Yiou, P., Ghil, M., 1992. Singular-spectrum analysis-a toolkit for short, noisy chaotic signals. Physica D 58, 95-126.

Veronis, G., 1973. Model of world ocean circulation: I. Wind driven, two-layer. Journal of Marine Research 31, 228-288. 